\title{
Analysis on the Temporal and Spatial Characteristics of the Shallow Soil Temperature of the Qinghai-Tibet Plateau
}

\section{Yujie Li}

Northwest Institute of Eco-Environment and Resources https://orcid.org/0000-0003-2163-9973

\section{Cunjie Zhang}

China Meteorological Administration, National Climate Center

\section{Zhenchao Li}

Northwest Institute of Eco-Environment and Resources

\section{Liwei Yang}

Northwest Institute of Eco-Environment and Resources

Xiao Jin

Northwest Institute of Eco-Environment and Resources

Xiaoqing Gao ( $\nabla$ xqgao@lzb.ac.cn )

Northwest Institute of Eco-Environment and Resources

\section{Research Article}

Keywords: Qinghai-Tibet Plateau, Shallow soil, Soil temperature, Climate change, Land surface process, land-atmosphere interaction

Posted Date: September 23rd, 2021

DOI: https://doi.org/10.21203/rs.3.rs-904007/v1

License: (c) (1) This work is licensed under a Creative Commons Attribution 4.0 International License. Read Full License 


\title{
Analysis on the Temporal and Spatial Characteristics of the Shallow
}

Soil Temperature of the Qinghai-Tibet Plateau

\author{
Yujie Li ${ }^{1,2}$ - Cunjie Zhang ${ }^{3}$ - Zhenchao Li ${ }^{1}$ - Liwei Yang1,2 • \\ Xiao Jin ${ }^{1} \cdot$ Xiaoqing Gao $^{1^{*}}$
}

${ }^{1}$ Key Laboratory of Land Surface Process and Climate Change in Cold and Arid

Regions of Chinese Academy of Sciences, Northwest Institute of Eco-Environment and

Resources, Chinese Academy of Sciences, 320, Donggang West Road, Lanzhou,

Gansu, 730000, China.

${ }^{2}$ University of Chinese Academy of Sciences, Beijing 100049, China.

${ }^{3}$ China Meteorological Administration, National Climate Center, Beijing, China

Corresponding author: Xiaoqing Gao, xqgao@1zb.ac.cn

\section{Acknowledgment.}

We thank the editors and reviewers for the constructive comments. We thank China Meteorological Administration, National Climate Center for the observational data. We also thank European Center for Medium-Range Weather Forecasts (ECMWF) for ERA5 data. This research supported by the Second Tibetan Plateau Scientific Expedition and Research Program (STEP), Grant No. 2019QZKK010303; Numerical Simulation Research on the Influence of Soil Temperature on Precipitation Forecast, Grant No. QHMS2019015; Key Talent Projects of Gansu Province in 2021. All authors declare that there is no conflict of interest.

Availability of data and material

The observational data in this work are come from the National Climate Centre, we thank Cunjie Zhang provided this dataset. The reanalysis data comes from European Center for Medium-Range Weather Forecasts, ECMWF (ERA5 hourly data on single levels from 1979 to present (copernicus.eu)).

\section{Declarations}

Conflict of interest The authors declares that they have no competing interest.

\section{Abstract}


Shallow soil refers to the soil layer within $50 \mathrm{~cm}$ underground. Shallow soil temperature (ST) affects many processes that occur in the soil. Therefore, the study of shallow ST is of great significance in understanding energy, hydrological cycles and climate change. This work collected the observational data from 141 meteorological stations on the Qinghai-Tibet Plateau from 1981 to 2020, analyzed the ST as well as its temporal and spatial change characteristics at different levels. The results show that: 1) The shallow ST has a gradually increasing trend from north to south, from west to east. From the perspective of time characteristics, the increasing trend is obvious. The temperature increase of $0-20 \mathrm{~cm}$ (the surface layer of the shallow soil) is roughly the same. The average annual is $9.15-9.57{ }^{\circ} \mathrm{C}$, the interdecadal variabilities are $0.49-0.53$ $\mathrm{K} / 10 \mathrm{a}$. The average annual of $40 \mathrm{~cm}$ (the bottom layer) is $8.69{ }^{\circ} \mathrm{C}$, the interdecadal variability reaches by $0.98 \mathrm{~K} / 10 \mathrm{a} ; 2)$ Judging from the 12 regions of $20 \mathrm{~cm}$, the temperature increase trend is obvious, but there are certain regional differences. The average value ranges from $4.3{ }^{\circ} \mathrm{C}$ (region 4 , Qaidam Plateau) to $18.1{ }^{\circ} \mathrm{C}$ (region 10, Southeast Qinghai-Tibet Plateau), the difference is nearly $14 \mathrm{~K}$. The standard deviation ranges from $0.38 \mathrm{~K}$ (region 10) to $0.82 \mathrm{~K}$ (region 11, Northern Qiangtang Plateau); 3) The results of the reanalysis data are lower than the observational data. This work is significant for understanding the characteristics of the ST evolution and the land-atmosphere interaction on the Qinghai-Tibet Plateau.

Keywords: Qinghai-Tibet Plateau · Shallow soil · Soil temperature · Climate change $\cdot$ Land surface process $\cdot$ land-atmosphere interaction

\section{Introduction}

The Qinghai-Tibet Plateau (QTP) is located in western China, including Tibet, Qinghai, southern Xinjiang, western Sichuan, southern Gansu, and northwestern Yunnan. The QTP spans more than $2500 \mathrm{~km}$ from east to west, and is about 1,000 kilometers from north to south. The total area is nearly $2.5 \times 10^{6} \mathrm{~km}^{2}$, accounting for about one-fourth of China's total area. It has an average elevation of $4000 \mathrm{~m}$, which accounts for almost one-third of the thickness of the troposphere. The QTP, often referred to as the Roof of the World or Third Pole, is known for its complex 
terrain and high altitude (Yang et al., 2014). QTP plays an important role in climate change and land-atmosphere interaction (Tang et al., 1979; Liu et al., 2000; Ma et al., 2011), its climate and ecological environment are jointly affected by westerly winds and Asian monsoons. In turn, the Qinghai-Tibet Plateau has also affected the regional and global climate change (Zhou et al., 2009). For example, the snow cover in winter and spring on the Qinghai-Tibet Plateau has a profound impact on temperature and precipitation in China and even in Asia (Wang et al., 2017; Wu et al., 2003). Changes in summer heat sources on the Qinghai-Tibet Plateau have a key impact on the evolution of the Asian monsoon (Duan et al., 2013; Park et al., 2012; Jiang et al., 2016). Many studies have shown that QTP is one of the most sensitive regions to global climate change (Su et al., 2011; Zhao et al., 2010). In recent decades, as the global climate has changed, the energy and water exchange of QTP has also changed correspondingly (Kang et al., 2010).

As an important part of the underlying surface of the land, soil is the lower boundary of material and energy exchange in the earth-atmosphere system (Dickinson, 1995). Soil temperature (ST) is one of the important parameters to characterize the thermal properties of soil, and it plays an important role in the research of many related fields (Huang et al., 2014). In terms of energy cycle, soil temperature affects climate change by affecting changes in surface energy. Therefore, the diagnosis and prediction of ST are important scientific and technical issues in land surface process models, numerical weather prediction and short-term climate prediction (Holmes et al., 1998). In terms of water cycle, ST greatly affects the process of sensible heat, latent heat and surface evapotranspiration. Changes in ST can further affect the temperature and precipitation of the Qinghai-Tibet Plateau and East Asia through the exchange of water between the atmosphere and the surface (Wang et al., 2013; Yang et al., 2007). In agricultural research, soil temperature is a driving environmental factor that affects crop growth, fertilizer decomposition and organic matter accumulation (Mackay et al., 1984; Kirschbaum, 1995). Considering meteorological research, the change of ST is a reliable indicator reflecting climate change. For example, the increase of ST in 
permafrost regions is an important indicator of permafrost degradation (Cheng et al., 2007; Luo et al., 2018b; Peng et al., 2016). The shallow ST is also one of the key factors of precipitation. Because the heat in the shallow soil can be easily released into the atmosphere, the abnormality of the shallow ST will affect the short-term weather process (Hu et al., 2005).

In view of the importance of soil temperature, many scholars have done a lot of work. In terms of the research on the temporal and spatial characteristics of soil temperature, ST has great differences on different time scales (daily, monthly, yearly) (Douville et al., 2016; Wu et al., 2013; Krarti et al., 1995). For example, ST has greater variability in the warmer months of the year (Kunkel et al., 2016; Liang et al., 2014). Snow cover in winter will affect the change of ST in high latitude areas (Mellander et al., 2007; Wundram et al.,2010). The ST in summer is greater than that in winter, and is positively correlated with soil depth (Samadianfard et al., 2018). Spatially, the relationship between the change of ST in different ecosystems is very different with altitude, slope, and vegetation cover types (Liu et al., 2011; Paul et al., 2004). Luo et al. (2013) showed that the ST in tropical rain forests is greater than that in temperate spruce forests, semi-humid and semi-arid grasslands, while the variability of ST is just the opposite. Taking into account the impact of ST on climate change, some scholars use continuously changing ST as boundary conditions in climate models to make the simulation of convection more accurate, thereby improving the simulation results of precipitation (Liu et al., 1999). Changes in soil temperature cause significant impacts on the land surface energy and water balance, and hence changes in weather and climate, surface and subsurface hydrology and ecosystem (Zhu et al. 2018; Zhou et al. 2020). Tang et al. (1987) conducted a series of research on the relationship between ST and precipitation, whose studies have shown that there is a good corresponding relationship between ST and later precipitation, and the ST at different levels has different continuity. The work of Qin et al. (2020) showed that the increasing trend of shallow ST in the Qinghai-Tibet Plateau in spring and summer is greater than that of deep soil; the temperature increase rate of shallow 
soil in autumn and winter is significantly lower than that of deep soil; the significant positive growth trend of the annual average ST indicates that the Qinghai-Tibet Plateau has responded to climate warming in the past few decades, and it is also regarded as one of the important indicators of permafrost degradation on the Qinghai-Tibet Plateau.

As one of the most sensitive areas of global climate change, the Qinghai-Tibet Plateau is an indispensable part of understanding the degradation of frozen soil, ecological environment and climate change. So far, most studies on ST in the Qinghai-Tibet Plateau are based on model results or reanalysis data from different sources. However, due to the harsh environmental conditions and the complex topography of the Qinghai-Tibet Plateau, the model parameters of the Qinghai-Tibet Plateau are not accurate enough. The soil temperature data obtained from the model has limitations and uncertainties (Guo et al., 2016; Wu et al., 2018b). The reanalysis data from different sources, because of the use of different assimilation systems, also differs from each other. So the model results and reanalysis data need to be verified by the site observation data. In this study, the shallow ST observation data from 141 meteorological stations on the Qinghai-Tibet Plateau from 1981 to 2020 are used to analyze the ST and its temporal and spatial change characteristics at different levels of the Qinghai-Tibet Plateau using fuzzy C-means clustering, linear fitting and linear regression. The shallow ST on the Qinghai-Tibet Plateau is divided and compared with the climate division of temperature and precipitation. This work is of great significance for understanding the evolution characteristics of ST and its climatic effects.

\section{Data and methods}

\subsection{Data selection}

The observational data in this work are the daily ST of 141 stations on the Qinghai-Tibet Plateau during the period of January 1, 1981, to December 31, 2020 by the National Climate Centre (Fig.1). The dataset has eight soil layers with depths of ground surface, $5,10,20,40,80,160$, and $320 \mathrm{~cm}$. In the northwestern part of the 


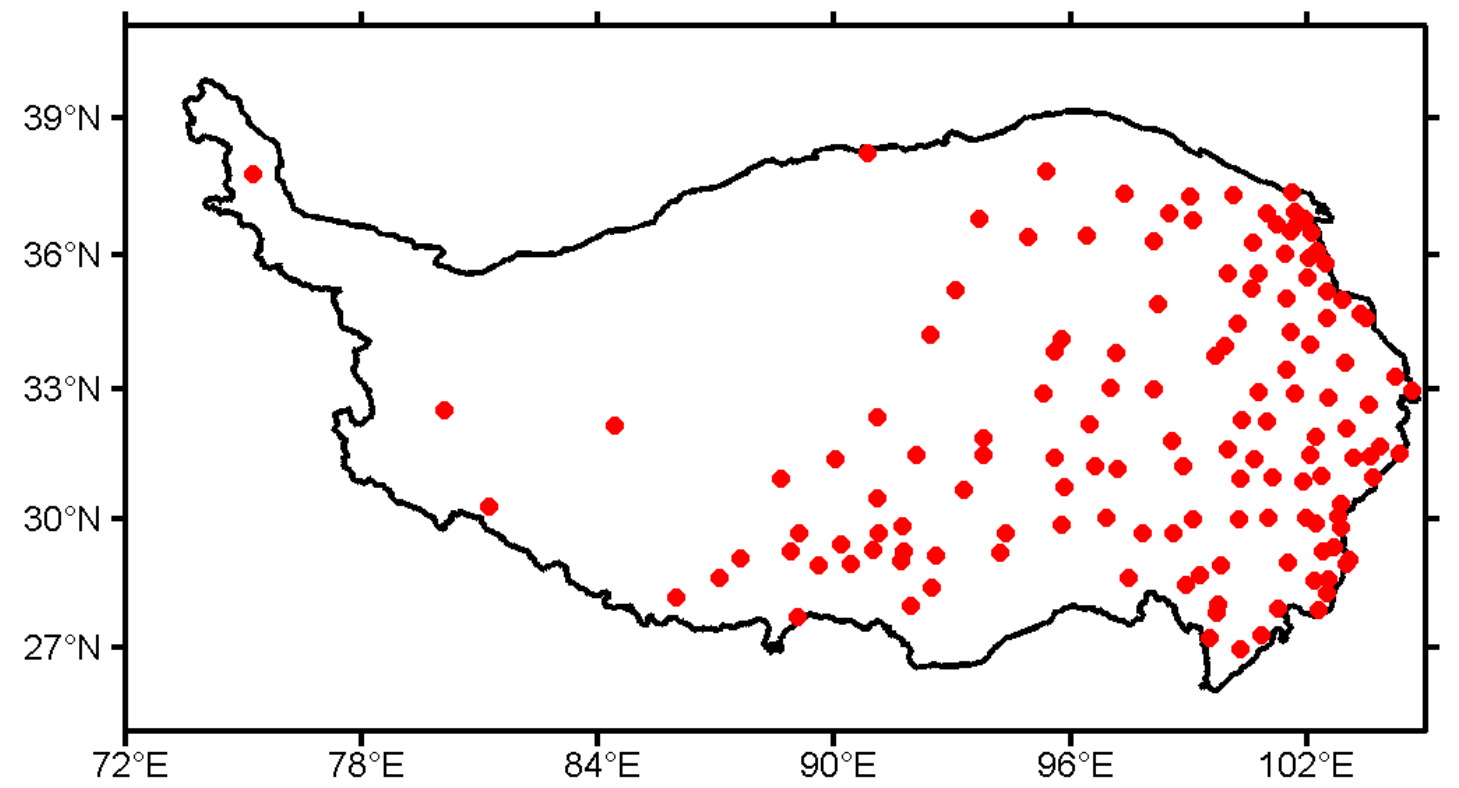

Fig.1 Soil temperature observatories on the Qinghai-Tibet Plateau has a four-layer representation of soil, where the surface is at $0 \mathrm{~cm}$ : Layer $1: 0-7 \mathrm{~cm}$, Layer 2: $7-28 \mathrm{~cm}$, Layer 3: $28-100 \mathrm{~cm}$, Layer 4: $100-289 \mathrm{~cm}$. ST is set at the middle of each layer, and heat transfer is calculated at the interfaces between them. It is assumed that there is no heat transfer out of the bottom of the lowest layer.

\subsection{Method}

\subsubsection{Fuzzy C-means algorithm (FCM)}

In this paper, the fuzzy C-means algorithm (FCM) is used to classify the annual average soil temperature of 141 ST observation sites in $20 \mathrm{~cm}$ on the Qinghai-Tibet Plateau from 1981 to 2020. Clustering is a method which divides a collection of abstract objects into different classes or clusters according to a certain standard (such as distance criterion, that is, the distance between different data), so that the similarity of data objects in the same cluster and the difference between different clusters is as great as possible (Saxena et al., 2017). The main idea of the FCM is to divide a number of L-dimensional vectors into $\mathrm{C}$ fuzzy groups, determine the degree of membership of each category by distance, and continuously update the membership 
degree as well as clustering center of image pixels to minimize the objective-function and complete pixel classification and image segmentation (Bezdek et al., 1984). The pixel membership degree is used to describe the degree to which the pixel belongs to a certain category, and the value range is $[0,1]$. The objective-function and restriction of the FCM algorithm are:

$$
J_{F C M}=\sum_{i=1}^{C} \sum_{j=1}^{N} u_{i j}^{m} d_{i j}^{2}\left(x_{j}, v_{i}\right), \quad \sum_{i=1}^{C} u_{i j}=1
$$

$u_{i j}=u_{j}\left(x_{j}\right)$ represents the degree to which the pixel gray $x_{j}$ belongs to category $i$, $m$ is the fuzzy weighting coefficient, often taken as $2, v_{i}=\left\{v_{1}, \ldots, v_{c}\right\}$ represent the $i-t h$ cluster centers, $d_{i j}\left(x_{j}, v_{i}\right)=\left\|x_{j}-v_{i}\right\|^{2}$ represents the shortest distance from the gray level of the $j-t h$ pixel to the $i-t h$ cluster center.

Using the Lagrangian multiplier method to find the minimum value of the objective function,

$$
\begin{gathered}
J_{\lambda}=\sum_{i=1}^{C} \sum_{j=1}^{N} u_{i j}^{m} d_{i j}^{2}\left(x_{j}, v_{i}\right)+\lambda\left(\sum_{j=1}^{c} u_{i j}-1\right) \\
v_{i}=\frac{\sum_{j=1}^{N} u_{i j}^{m} x_{j}}{\sum_{j=1}^{N} u_{i j}^{m}}(i=1, \ldots, C) \\
u_{i j}=\frac{1}{\sum_{k=1}^{N}\left(\frac{d\left(x_{j}, v_{i}\right)}{d\left(x_{j}, v_{k}\right)}\right)^{2(m-1)}}
\end{gathered}
$$

The standard FCM algorithm is superior in simple image segmentation. In recent years, FCM has been widely used in research fields such as climate region division, pattern recognition, data analysis and image processing, showing that the FCM can clearly represent the continuous spatial distribution of natural phenomena (Lee, 2009).

\subsubsection{Mann-Kendall mutation analysis}

The change of ST is synergistically affected by many factors, so it can show the characteristics of trend change. Mann-Kendall (M-K) (Mann, 1945; Kendall, 1975) test is not affected by the sample value, distribution type, etc., and further analyzes the changing of variables by deeply mining the hidden information within the time series. Therefore, it is widely used in the research of time analysis of natural variables. 
Given the time series variables $\left(X_{1}, X_{2}, \ldots, X_{n}\right)$, where $n$ is the length of $X$, define the statistic $S$ as follows:

$$
\mathrm{S}=\sum_{k=1}^{n-1} \sum_{j=k+1}^{n} \operatorname{Sgn}\left(x_{j}-x_{k}\right)
$$

$\operatorname{Sgn}()$ is a symbolic function, which can be expressed as:

$$
\operatorname{Sgn}\left(x_{j}-x_{k}\right)=\left\{\begin{array}{c}
1, x_{j}-x_{k}>0 \\
0, x_{j}-x_{k}=0 \\
-1, x_{j}-x_{k}<0
\end{array}\right.
$$

Among them, $S$ has a normal distribution whose mean is 0 ; the variance $\operatorname{Var}(S)=$ $\frac{n(n-1)(2 n+5)}{18}$, when $n>10$, the normal distribution statistics are calculated as follows:

$$
\mathrm{Z}=\left\{\begin{array}{l}
\frac{s-1}{\sqrt{\operatorname{Var}(s)}}, s>0 \\
0, s=0 \\
\frac{s+1}{\sqrt{\operatorname{Var}(s)}}, s<0
\end{array}\right.
$$

If $\mathrm{Z}>0$, it indicates that the natural variable has an increasing trend during this period of time; if $\mathrm{Z}<0$, the natural variable has a decreasing trend. The larger the absolute value, the more obvious the trend is. When $|\mathrm{Z}| \geq 1.28,1.96$, and 2.32 , they passed $90 \%, 95 \%$, and $99 \%$ reliability tests, respectively.

\subsubsection{Moving Surface Spline Interpolation Algorithm Based on Green's Function}

The data of 141 ST observation stations on the Qinghai-Tibet Plateau are interpolated by Moving Surface Spline Interpolation Algorithm Based on Green's Function. Compared with Shepard (IDW interpolation), Bivariate Cubic Polynomial Fitting, Local Neighborhood Kriging, Ordinary Kriging, Moving Surface Spline Interpolation, etc., this method has higher accuracy and better continuity when dealing with complex terrain and different underlying surface conditions (Deng and Tang 2011).

The solution of Green's functions implies that the surface $s(x)$ can be expressed as

$$
s(x)=T(x)+\sum_{j=1}^{n} w_{j} g\left(x, x_{j}\right)
$$


214 where $x$ is the output position vector of the unknown data point, $g\left(x, x_{j}\right)$ is the 215 Green's function, $x_{j}$ is the $\mathrm{j}$-th data constraint, and $w_{j}$ are the associated unknown 216 weight relative to $x . T(x)$ is the trend function (Wessel 2009). The weight $w_{j}$ are 217 determined by requiring (1) to be accurately satisfied in $\mathrm{n}$ data positions,

$$
s\left(x_{i}\right)=\sum_{j=1}^{n} w_{j} g\left(x_{i}, x_{j}\right), i=1,2, \ldots, n .
$$

$$
g\left(x_{i}, x_{j}\right)=\left|x_{i}, x_{j}\right|^{2} \ln \left(\left|x_{i}, x_{j}\right|\right)
$$

The steps of the Moving Surface Spline Interpolation Algorithm Based on Green's Function are as follows:

Part 1. Assuming a surface has total $n$ known points, the desired output node is $p_{0}$.

The number of points nearest to $p_{0}$ used for interpolation is $k$. The distance from

$$
r_{0 i}=\left|x_{i}, x_{0}\right|, i=1,2, \ldots, n
$$

Where $r_{0 i}$ is the distance between the point $p_{0}$ and the $i-t h$ known data point, $x_{0}$ is the position vector of $p_{0}$, and $x_{i}$ is the position vector of the $i-t h$ known data point.

Part 2. Setting the coordinate matrix $X=\left[x_{1} x_{2} \ldots x_{k}\right]^{T}, \quad Y=\left[y_{1} y_{2} \ldots y_{k}\right]^{T}$, attribute matrix $Z=\left[z_{1} z_{2} \ldots z_{k}\right]^{T}, k \times k$ Green's function matrix $G$ is:

$$
\begin{gathered}
G=\left[\begin{array}{cccc}
d_{11} & d_{12} & \cdots & d_{1 k} \\
d_{21} & d_{22} & \cdots & d_{2 k} \\
\vdots & \vdots & \ddots & \vdots \\
d_{k 1} & d_{k 2} & \cdots & d_{k k}
\end{array}\right] \\
d_{i j}=\left\{\begin{array}{ccc}
0 \quad & r_{i j}=0 \\
{\left[\ln \left(r_{i j}\right)-1.0\right] r_{i j}^{2}} & r_{i j} \neq 0
\end{array}\right.
\end{gathered}
$$

where $r_{i j}=\sqrt{\left(x_{i}-x_{j}\right)^{2}+\left(y_{i}-y_{j}\right)^{2}}$. the weight matrix $W$ can be calculated as

$$
W=G^{-1} Z
$$

Part 3. Computing $1 \times k$ Green's function matrix $G_{p}$ of point $p_{0}$

$$
G_{p}=\left[d_{01} d_{02} \cdots d_{0 k}\right]
$$

where $d_{01}, d_{02}, \cdots, d_{0 k}$ are calculated by (13). The attribute value of point $p_{0}$ is

$$
z_{p}=G_{p} W
$$

Part 4. Repeat Parts (1)-(3) to calculate the interpolation $z_{p i}$ of other points $p_{i}$. 


\section{Results}

3.1. Temporal and spatial distribution of shallow layers ST on the Qinghai-Tibet Plateau

\subsubsection{The spatial distribution}

Fig. 2 shows the spatial distribution of the annual average ST in the shallow layers of the Qinghai-Tibet Plateau (surface, $5 \mathrm{~cm}, 10 \mathrm{~cm}, 15 \mathrm{~cm}, 20 \mathrm{~cm}, 40 \mathrm{~cm}$ ). It can be seen from the figure that the shallow ST of the Qinghai-Tibet Plateau has a gradually increasing trend from north to south, but there is a relatively high ST area in Golmud, Qinghai, with an average of $5-10{ }^{\circ} \mathrm{C}$. In the vast areas of the Northern Qiangtang Plateau and the Southern Qiangtang Plateau, the shallow ST is basically below $5{ }^{\circ} \mathrm{C}$.

The temperature in the southeastern Tibet and the western Sichuan plateau is high, reaching above $20^{\circ} \mathrm{C}$.
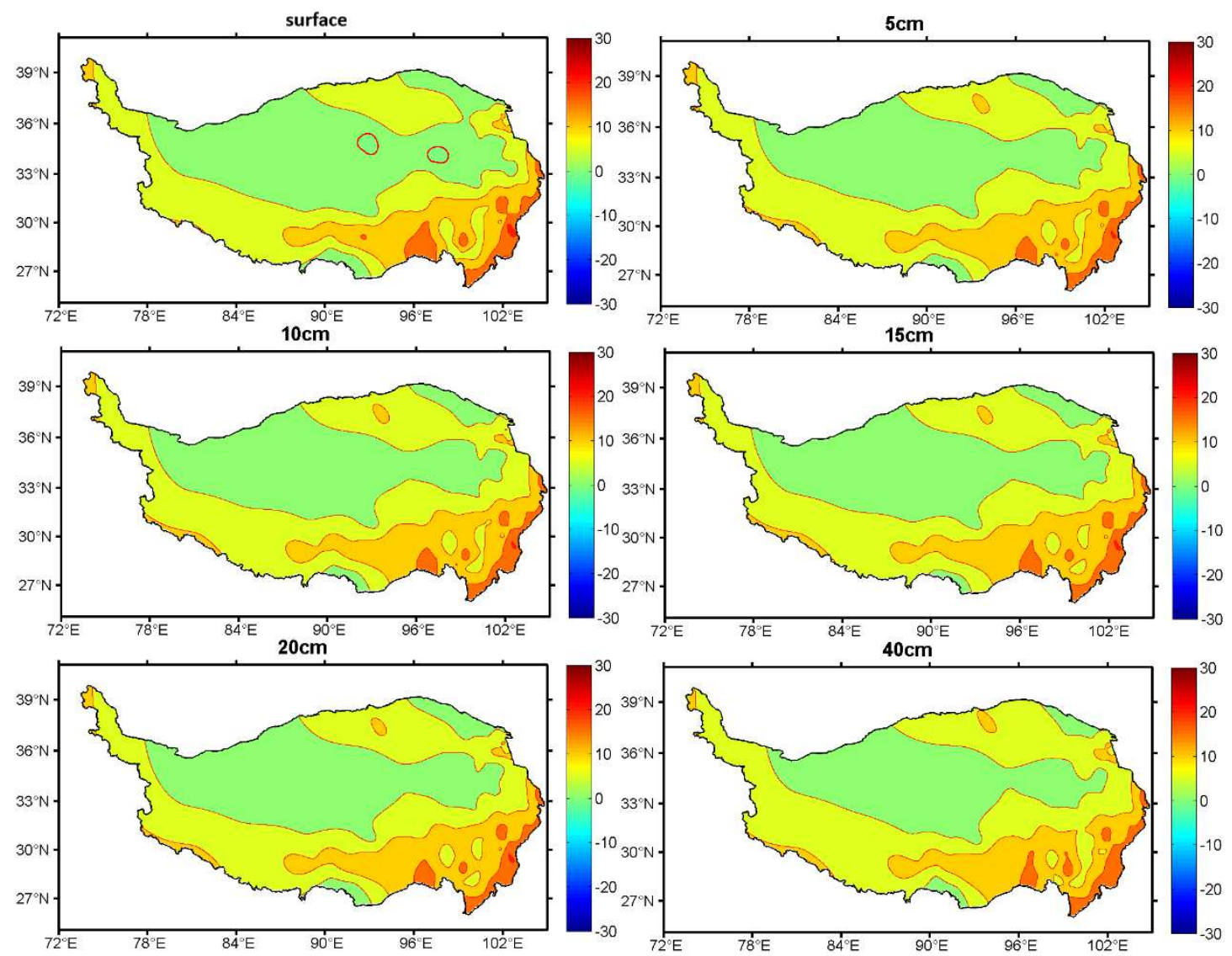

Fig. 2. Spatial distribution of shallow ST on the Qinghai-Tibet Plateau (unit: ${ }^{\circ} \mathrm{C}$ )

\subsubsection{Temporal characteristics}

Fig. 3 and 4 show the interannual variation of ST anomalies in shallow layer 
256 (surface, $5 \mathrm{~cm}, 10 \mathrm{~cm}, 15 \mathrm{~cm}, 20 \mathrm{~cm}, 40 \mathrm{~cm}$ ) of the Qinghai-Tibet Plateau and their

257 MK tests. It can be seen that from 1981 to 2020, ST at the six levels has shown a

258 significant upward trend, but the rising amplitudes of each level are quite different.

259 From the MK tests in Fig. 4, it can be seen that $5 \mathrm{~cm}, 10 \mathrm{~cm}, 15 \mathrm{~cm}$, and $20 \mathrm{~cm}$ have 260 insignificant mutation points near 2008. Besides, $40 \mathrm{~cm}$ and the surface have 261 mutations near 2002. Table 1 is the statistical information of the annual and seasonal temperature of the shallow soil on the Qinghai-Tibet Plateau, including the average, standard deviation, and interdecadal variability. On an annual scale, the average annual ST of $0-20 \mathrm{~cm}$ is $9.15-9.57{ }^{\circ} \mathrm{C}$, and that of $40 \mathrm{~cm}$ is $8.69^{\circ} \mathrm{C}$. The interdecadal variability of $0-20 \mathrm{~cm}$ is $0.49-0.53 \mathrm{~K} / 10 \mathrm{a}$, and the interdecadal variability of $40 \mathrm{~cm}$ reaches $0.98 \mathrm{~K} / 10 \mathrm{a}$, which is much higher than other levels. From the seasonal perspective, the interdecadal variability of ST in winter and spring is relatively high, with $40 \mathrm{~cm}$ even reaching more than $1 \mathrm{~K} / 10 \mathrm{a}$. In addition, the $40 \mathrm{~cm}$ interannual and seasonal ST standard deviation $(1.13-1.44 \mathrm{~K})$ is much larger than other layers $(\sigma<1 \mathrm{~K})$, indicating that ST in $40 \mathrm{~cm}$ varies more greatly. This result is reflected in the mutation point in 2002-2006 of Fig. 3(e1) and 2002 of Fig. 4(e). The analysis shows that the temperature of the shallow soil on the Qinghai-Tibet Plateau has a clear increasing trend. The temperature increase of $0-20 \mathrm{~cm}$ (the surface layer of shallow soil) is roughly the same, which is quite different from that of $40 \mathrm{~cm}$ (the bottom layer of shallow soil). 

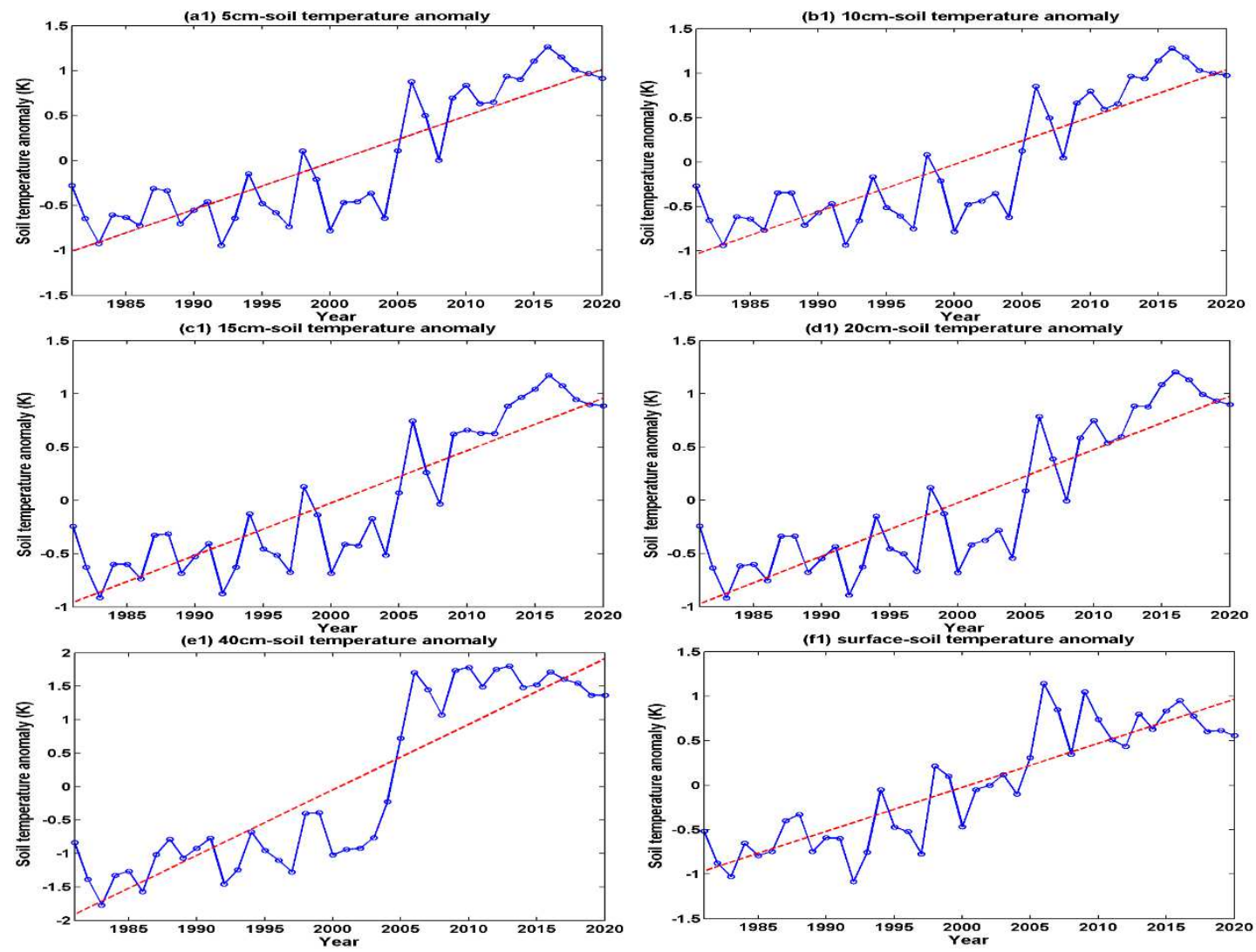

Fig. 3. Interannual variation of shallow ST anomaly in the Qinghai-Tibet Plateau (unit:

$\mathrm{K})$
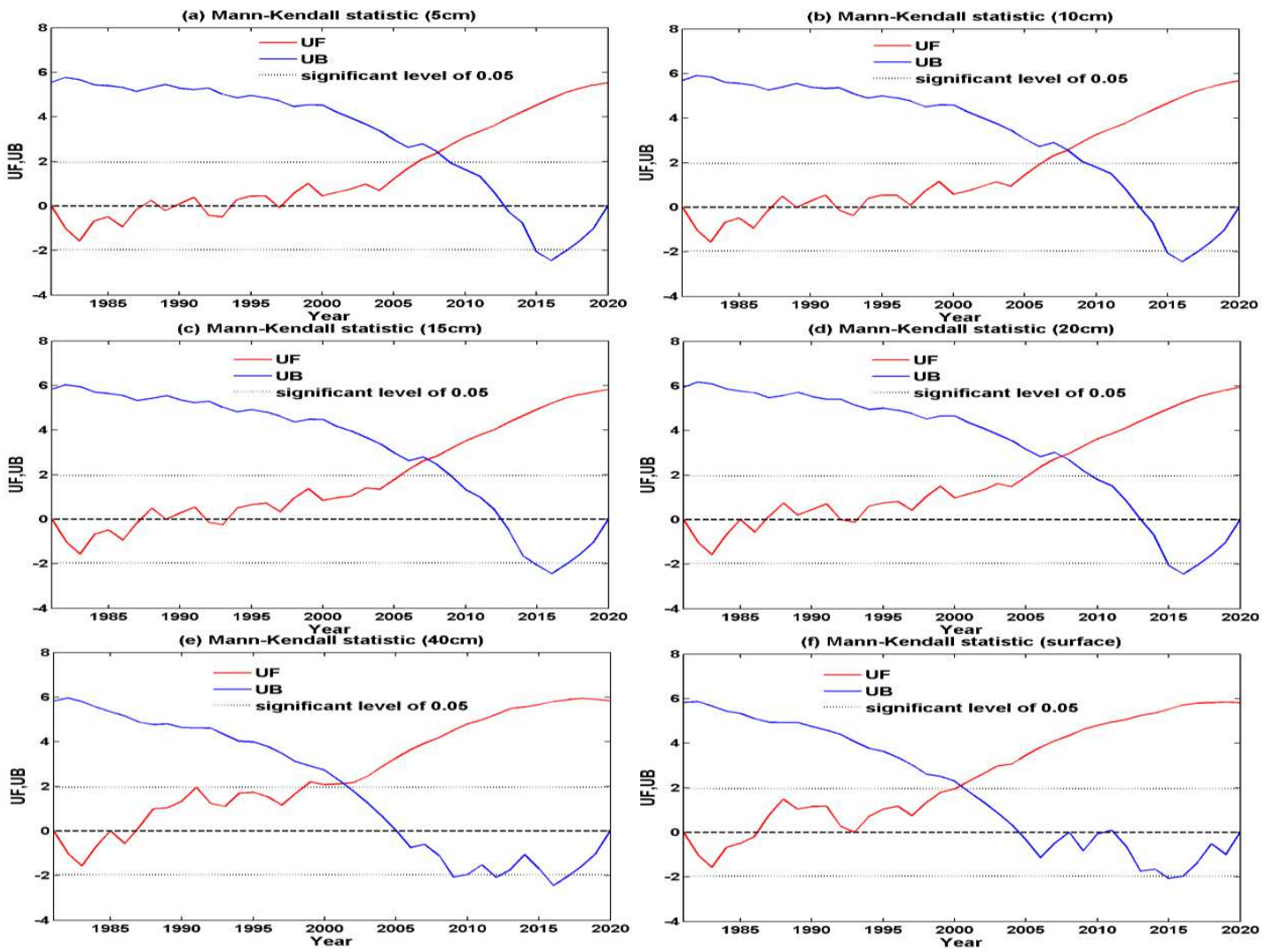

Fig. 4. MK analysis of shallow ST on the Qinghai-Tibet Plateau 
Table 1. Statistical information of annual and seasonal meteorological time series on the Qinghai-Tibet Plateau from 1981 to 2020

\begin{tabular}{|c|c|c|c|c|c|c|}
\hline & \multicolumn{3}{|c|}{$5 \mathrm{~cm}$} & \multicolumn{3}{|c|}{$10 \mathrm{~cm}$} \\
\hline & $\begin{array}{c}\boldsymbol{\mu} \\
\left({ }^{\circ} \mathbf{C}\right)\end{array}$ & $\begin{array}{c}\sigma \\
(\mathbf{K})\end{array}$ & $\begin{array}{c}\text { Trend } \\
\text { (K/10a) }\end{array}$ & $\begin{array}{c}\boldsymbol{\mu} \\
\left({ }^{\circ} \mathbf{C}\right)\end{array}$ & $\begin{array}{c}\boldsymbol{\sigma} \\
(\mathbf{K})\end{array}$ & $\begin{array}{r}\text { Trend } \\
(\mathbf{K} / \mathbf{1 0 a})\end{array}$ \\
\hline Spring & 10.19 & 0.78 & $0.55^{* *}$ & 9.74 & 0.85 & $0.61 * *$ \\
\hline Summer & 18.42 & 0.65 & $0.39 * *$ & 18.15 & 0.70 & $0.45^{* *}$ \\
\hline Autumn & 9.42 & 0.77 & $0.51 * *$ & 9.81 & 0.75 & $0.50 * *$ \\
\hline Winter & -1.43 & 0.93 & $0.63 * *$ & -0.96 & 0.83 & $0.55^{* *}$ \\
\hline \multirow[t]{4}{*}{ Annual } & 9.15 & 0.71 & $0.52 * *$ & 9.19 & 0.72 & $0.53 * *$ \\
\hline & \multicolumn{3}{|c|}{$15 \mathrm{~cm}$} & \multicolumn{3}{|c|}{$20 \mathrm{~cm}$} \\
\hline & $\mu$ & $\sigma$ & Trend & $\boldsymbol{\mu}$ & $\sigma$ & Trend \\
\hline & $\left({ }^{\circ} \mathbf{C}\right)$ & $(\mathbf{K})$ & (K/10a) & $\left({ }^{\circ} \mathbf{C}\right)$ & $(\mathbf{K})$ & $(\mathbf{K} / \mathbf{1 0 a})$ \\
\hline Spring & 9.27 & 0.74 & $0.48 * *$ & 9.05 & 0.83 & $0.60 * *$ \\
\hline Summer & 17.87 & 0.63 & $0.37 * *$ & 17.62 & 0.67 & $0.45^{* *}$ \\
\hline Autumn & 10.28 & 0.71 & $0.49 * *$ & 10.41 & 0.68 & $0.46^{* *}$ \\
\hline Winter & -0.30 & 0.70 & $0.62 * *$ & -0.17 & 0.71 & $0.48 * *$ \\
\hline \multirow[t]{4}{*}{ Annual } & 9.28 & 0.66 & $0.49 * *$ & 9.22 & 0.67 & $0.50 * *$ \\
\hline & \multicolumn{3}{|c|}{$40 \mathrm{~cm}$} & \multicolumn{3}{|c|}{ surface } \\
\hline & $\boldsymbol{\mu}$ & $\sigma$ & Trend & $\boldsymbol{\mu}$ & $\sigma$ & Trend \\
\hline & $\left({ }^{\circ} \mathbf{C}\right)$ & $(\mathbf{K})$ & $(\mathrm{K} / 10 \mathrm{a})$ & $\left({ }^{\circ} \mathbf{C}\right)$ & $(\mathbf{K})$ & $(\mathbf{K} / \mathbf{1 0 a})$ \\
\hline Spring & 7.65 & 1.51 & $1.14 * *$ & 11.17 & 0.75 & $0.51 * *$ \\
\hline Summer & 16.46 & 1.13 & $0.84 * *$ & 19.51 & 0.61 & $0.30 * *$ \\
\hline Autumn & 10.58 & 1.17 & $0.87 * *$ & 9.38 & 0.75 & $0.51 * *$ \\
\hline Winter & 0.06 & 1.44 & $1.06 * *$ & -1.79 & 0.96 & $0.66^{* *}$ \\
\hline Annual & 8.69 & 1.29 & $0.98 * *$ & 9.57 & 0.66 & $0.49 * *$ \\
\hline
\end{tabular}

$283 \boldsymbol{\mu}$ mean, $\boldsymbol{\sigma}$ standard deviation

$284 * *$ Denotes trends statistically significant at $\alpha=0.001$

285 3.1.3 Characteristics of spatial changes in shallow soils on the Qinghai-Tibet Plateau 
Fig. 5 shows the interdecadal distribution of ST in shallow layer (surface, $5 \mathrm{~cm}, 10$ $\mathrm{cm}, 15 \mathrm{~cm}, 20 \mathrm{~cm}, 40 \mathrm{~cm}$ ) of the 141 observation sites on the Qinghai-Tibet Plateau from 1981 to 2020 . As shown in the figure, the interdecadal variabilities of $5-20 \mathrm{~cm}$ (the surface layer of the shallow soil) is basically the same. In the central Tibet, the southern and southwestern parts of the Qinghai-Tibet Plateau, ST has a significant cooling trend, and the interdecadal variabilities are as low as $-1 \mathrm{~K} / 10 \mathrm{a}$. In the northwestern part of the Qinghai-Tibet Plateau, ST is warming obviously. Compared with other layers, $40 \mathrm{~cm}$ (the bottom layer of shallow soil) is quite different. On the whole, the temperature increase trend of $40 \mathrm{~cm}$ is more obvious than that of other layers. The cooling trend still exists in central Tibet, the warming trend in the northwestern Qinghai-Tibet Plateau has slightly weakened, while the cooling trend of ST in southwestern Tibet has turned into a warming trend, and the Qaidam Plateau has a significant warming trend. The surface of the Qinghai-Tibet Plateau has a warming trend, but the temperature change does not have the obvious regional differentiation like other levels.
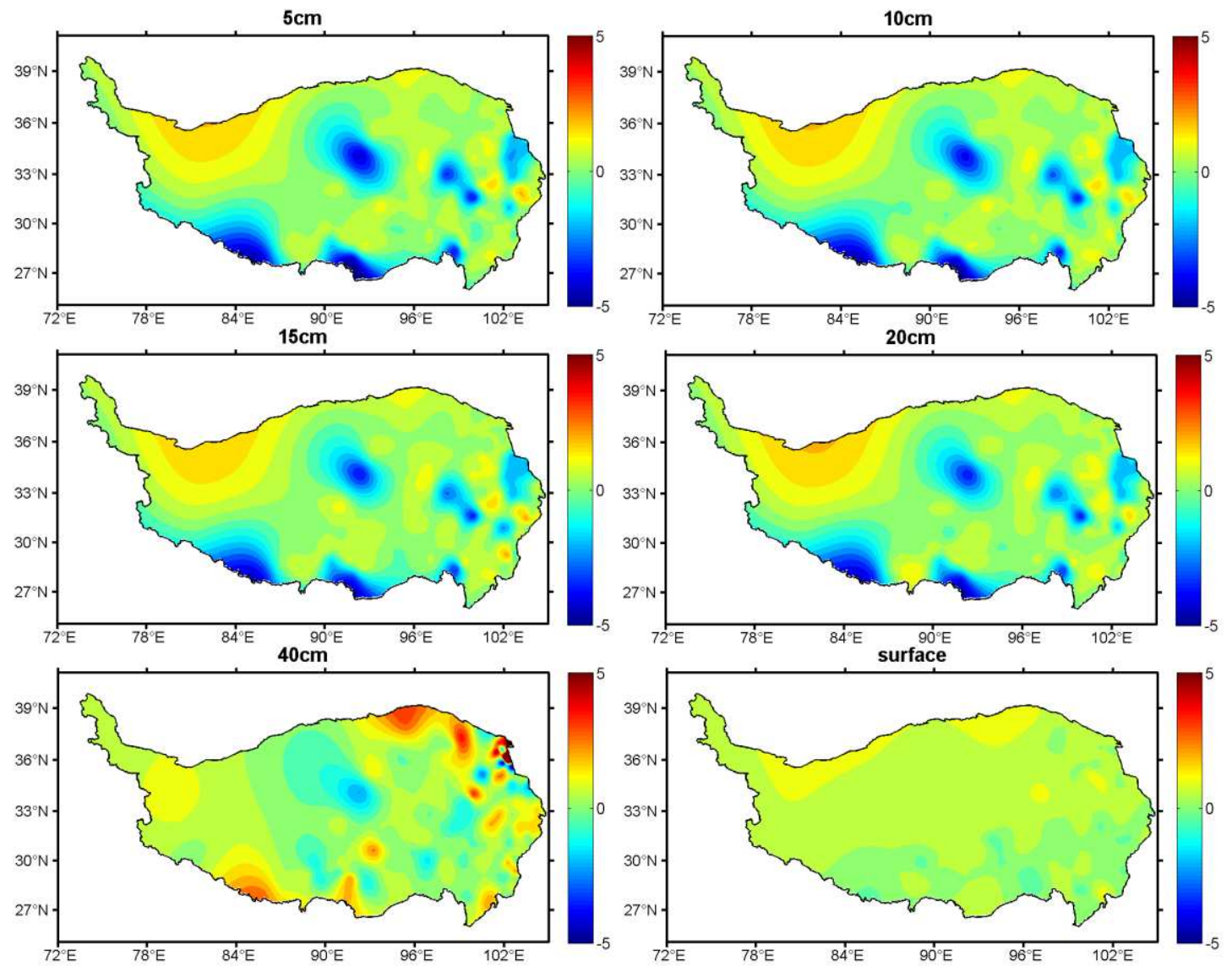
Fig. 5. Distribution of interdecadal variability of ST in shallow soil on the Qinghai-Tibet Plateau from 1981 to 2020 (unit: K/10 a)

\subsection{Analysis of $20 \mathrm{~cm} \mathrm{ST} \mathrm{characteristics} \mathrm{of} \mathrm{the} \mathrm{Qinghai-Tibet} \mathrm{Plateau}$}

\subsubsection{Regionalization of $20 \mathrm{~cm} \mathrm{ST}$}

$20 \mathrm{~cm}$ is basically the same as $5 \mathrm{~cm}, 10 \mathrm{~cm}$, and $15 \mathrm{~cm}$, and $20 \mathrm{~cm}$ is the boundary layer between the surface layer of shallow soil and the bottom layer of shallow soil (Yan et al., 2017). Therefore, the study of the $20 \mathrm{~cm} \mathrm{ST}$ is significant for the macroscopic understanding of the shallow ST of the Qinghai-Tibet Plateau.

Fig. 6 shows the $20 \mathrm{~cm}$ ST division of the Qinghai-Tibet Plateau, using fuzzy C-means algorithm (FCM). In the process of FCM clustering, choosing the appropriate fuzzy index $m$ and the number of categories $C$ is the most critical. According to the research of Liu et al. (2014), the expected clustering effect can be achieved when $m=2$. The choice of category number $C$ is related to the change of entropy $\left(\delta H, H_{c}-H_{c+1}\right)$ and the change of distribution coefficient $\left(\delta F, F_{c}-F_{c+1}\right)$. When the change of distribution coefficient is the smallest and the change of entropy is the largest, $C$ is determined. Using FCM, based on $20 \mathrm{~cm} \mathrm{ST}$ at 141 sites on the Qinghai-Tibet Plateau, 12 regions were clustered. The classification results are shown in Fig. 7, and the environmental parameters of the cluster centers are shown in Table 2 .

Using FCM, the Qinghai-Tibet Plateau is divided into 12 regions according to the characteristics of the $20 \mathrm{~cm} \mathrm{ST}$. Considered with the 13 climate regions of the Qinghai-Tibet Plateau by Lin et al. (1981), the $20 \mathrm{~cm}$ ST regions and many regions of the climate division, such as the Western Sichuan Plateau, Xining Plateau, Qaidam Plateau, Nagqu Plateau, Eastern Qinghai-Tibet Plateau and Eastern Tibet Plateau have high consistency. This also shows that the shallow soil, especially the surface of the shallow soil, is greatly affected by the local climate characteristics (air temperature and precipitation, Lin et al. divided the Qinghai-Tibet Plateau into 13 regions using air temperature and precipitation). 


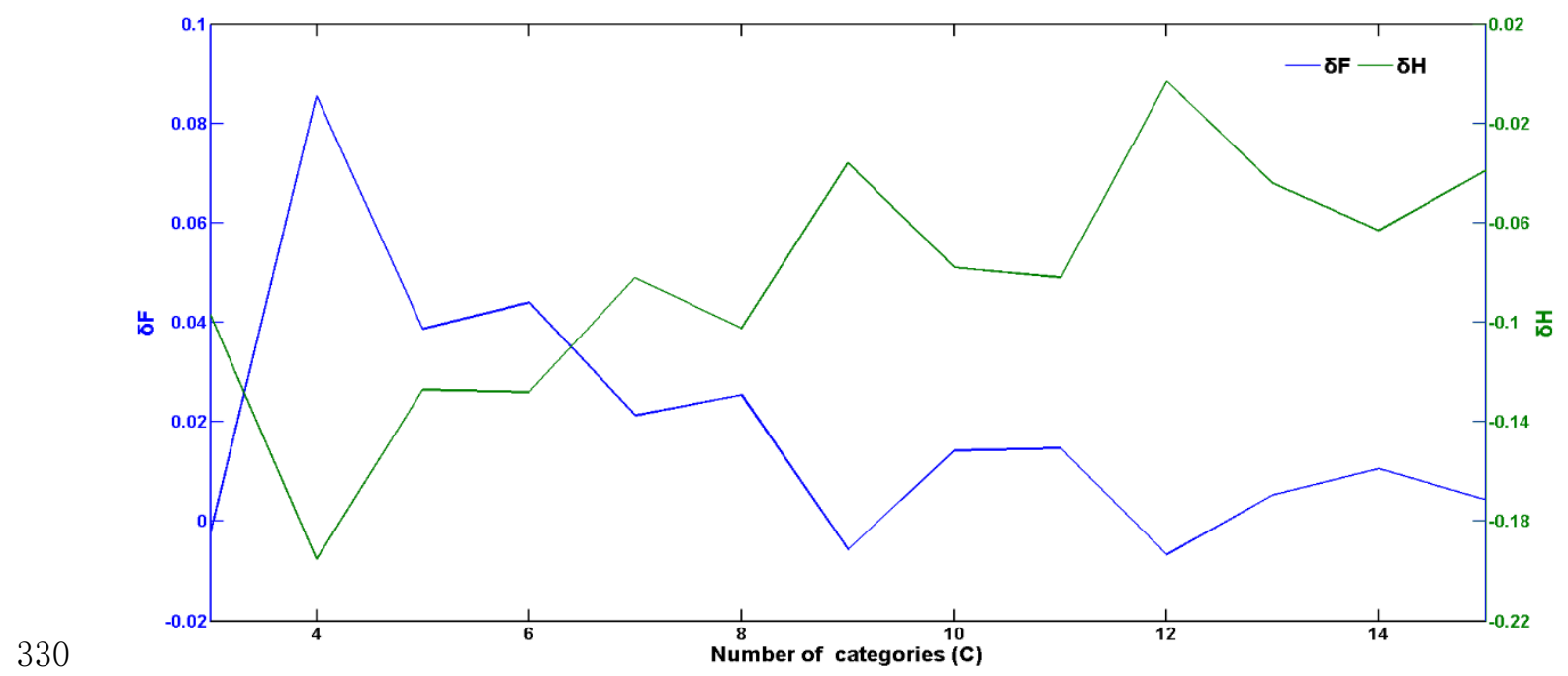

Fig. 6. When $\mathrm{m}=2.0$, the entropy and distribution coefficient change with the number of categories $(C)$

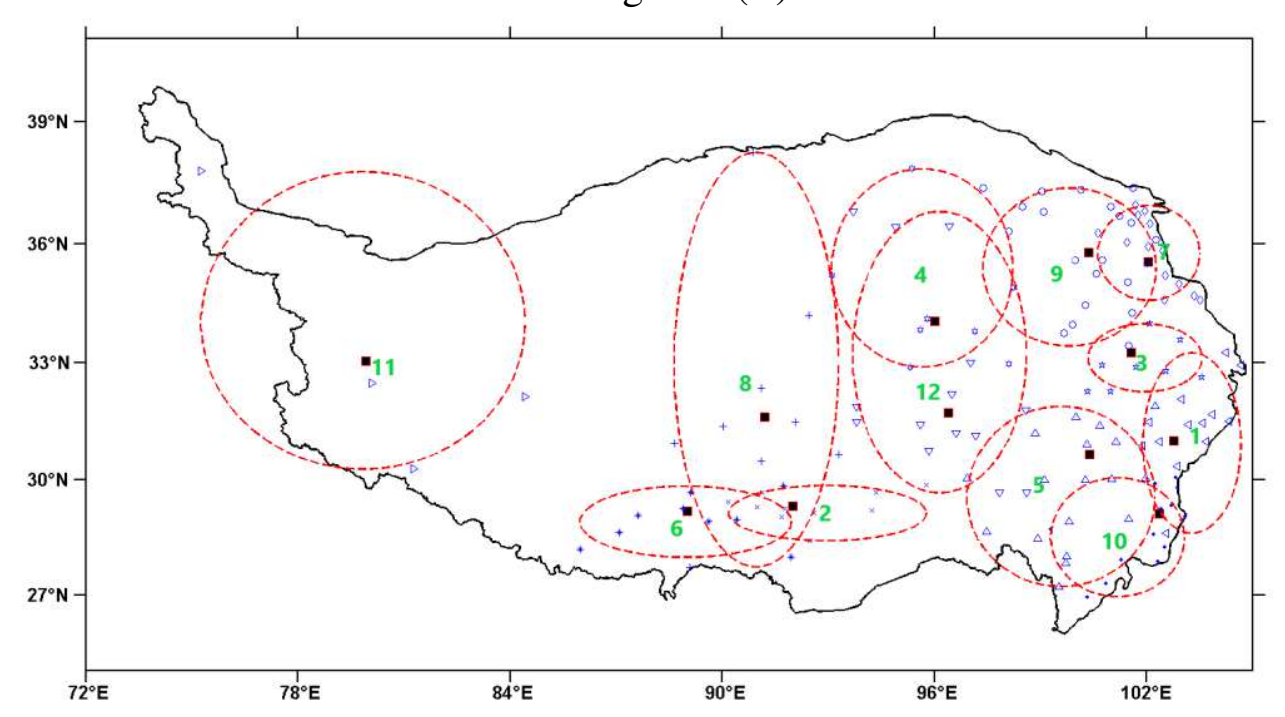

Fig. 7. 20cm ST division of the Qinghai-Tibet Plateau (12 regions)

Table 2. Environmental parameters of the region center

\begin{tabular}{|c|c|c|c|c|c|c|}
\hline $\begin{array}{l}\text { Region } \\
\text { Numb- } \\
\text { er }\end{array}$ & $\begin{array}{c}\text { Region } \\
\text { name }\end{array}$ & $\begin{array}{c}\text { Longit- } \\
\text { ude } \\
\left({ }^{\circ} \mathbf{E}\right)\end{array}$ & $\begin{array}{l}\text { Latitude } \\
\left({ }^{\circ} \mathbf{N}\right)\end{array}$ & $\begin{array}{c}\boldsymbol{\mu} \\
\left({ }^{\circ} \mathbf{C}\right)\end{array}$ & $\begin{array}{c}\sigma \\
(\mathbf{K})\end{array}$ & $\begin{array}{c}\text { Trend } \\
(\mathrm{K} / \mathbf{1 0 a})\end{array}$ \\
\hline $\begin{array}{c}\text { Region } \\
1\end{array}$ & $\begin{array}{c}\text { Western Sichuan } \\
\text { Plateau }\end{array}$ & 102.7 & 31.1 & 15.6 & 0.51 & 0.30 \\
\hline $\begin{array}{l}\text { Region } \\
\quad 2\end{array}$ & Southern Tibet I & 92.1 & 29.3 & 12.5 & 0.56 & 0.38 \\
\hline $\begin{array}{l}\text { Region } \\
\quad 3\end{array}$ & $\begin{array}{c}\text { Eastern } \\
\text { Qinghai-Tibet } \\
\text { Plateau }\end{array}$ & 101.2 & 33.3 & 7.8 & 0.59 & 0.44 \\
\hline $\begin{array}{l}\text { Region } \\
\quad 4\end{array}$ & Qaidam Plateau & 95.9 & 34.0 & 4.3 & 0.53 & 0.39 \\
\hline $\begin{array}{l}\text { Region } \\
5\end{array}$ & $\begin{array}{c}\text { Eastern Tibet } \\
\text { Plateau }\end{array}$ & 100.2 & 30.8 & 11.5 & 0.42 & 0.24 \\
\hline & & & 16 & & & \\
\hline
\end{tabular}




\begin{tabular}{|c|c|c|c|c|c|c|}
\hline $\begin{array}{l}\text { Region } \\
\quad 6\end{array}$ & $\begin{array}{c}\text { Southern Tibet } \\
\text { II }\end{array}$ & 88.9 & 29.2 & 9.3 & 0.58 & 0.39 \\
\hline $\begin{array}{c}\text { Region } \\
7\end{array}$ & Xining Plateau & 102.2 & 34.2 & 9.1 & 0.47 & 0.31 \\
\hline $\begin{array}{c}\text { Region } \\
8\end{array}$ & Central Tibet & 91.3 & 31.4 & 4.9 & 0.50 & 0.22 \\
\hline $\begin{array}{c}\text { Region } \\
9\end{array}$ & Nagqu Plateau & 100.1 & 35.4 & 5.3 & 0.61 & 0.46 \\
\hline $\begin{array}{c}\text { Region } \\
10\end{array}$ & $\begin{array}{c}\text { Southeast } \\
\text { Qinghai-Tibet } \\
\text { Plateau }\end{array}$ & 102.4 & 29.2 & 18.1 & 0.38 & 0.21 \\
\hline $\begin{array}{c}\text { Region } \\
11\end{array}$ & $\begin{array}{c}\text { Northern } \\
\text { Qiangtang } \\
\text { Plateau }\end{array}$ & 80.1 & 32.8 & 7.1 & 0.82 & 0.61 \\
\hline $\begin{array}{c}\text { Region } \\
12\end{array}$ & $\begin{array}{c}\text { Tibet Middle } \\
\text { East }\end{array}$ & 96.4 & 31.7 & 8.2 & 0.57 & 0.42 \\
\hline
\end{tabular}

3.2.2 The characteristics of interannual variation of $20 \mathrm{~cm}$ ST on the different regions of Qinghai-Tibet Plateau

Fig. 8 shows the interannual variation of the $20 \mathrm{~cm} \mathrm{ST}$ anomaly in 12 regions of the

Qinghai-Tibet Plateau. According to Fig. 8 and Table 2, from 1981 to 2020, ST of 20 $\mathrm{cm}$ in 12 regions showed an obvious rising trend, but the rise of each region was quite different. Linear fitting of ST for each region shows that the interdecadal variability of region 1 is $0.30 \mathrm{~K} / 10 \mathrm{a}$, region 2 is $0.38 \mathrm{~K} / 10 \mathrm{a}$, region 3 is $0.44 \mathrm{~K} / 10 \mathrm{a}$, region 4 is 0.39 $\mathrm{K} / 10 \mathrm{a}$, region 5 is $0.24 \mathrm{~K} / 10 \mathrm{a}$, region 6 is $0.39 \mathrm{~K} / 10 \mathrm{a}$, region 7 is $0.31 \mathrm{~K} / 10 \mathrm{a}$, region 8 is $0.22 \mathrm{~K} / 10 \mathrm{a}$, region 9 is $0.46 \mathrm{~K} / 10 \mathrm{a}$, region 10 is $0.21 \mathrm{~K} / 10 \mathrm{a}$, region 11 is $0.61 \mathrm{~K} / 10 \mathrm{a}$, and region 12 is $0.37 \mathrm{~K} / 10 \mathrm{a}$. And the correlation coefficients with the month are 0.40 , $0.51,0.55,0.54,0.38,0.50,0.45,0.29,0.60,0.32,0.65,0.61$, all of which passed the confidence level $t$ test with $\alpha=0.001$. The average values of different regions range from $4.3{ }^{\circ} \mathrm{C}$ (region 4, Qaidam Plateau) to $18.1{ }^{\circ} \mathrm{C}$ (region 10, Southeast Qinghai-Tibet Plateau), and the average difference is nearly $14 \mathrm{~K}$. The standard deviation of different regions ranges from $0.38 \mathrm{~K}$ (region 10, Southeast Qinghai-Tibet Plateau) to $0.82 \mathrm{~K}$ (region 11, Northern Qiangtang Plateau). Because the Southeast Qinghai-Tibet Plateau is located in a humid climate area, the shallow ST changes little, while the North Qiangtang Plateau is located in an arid climate area, and the seasonal temperature difference is larger, so the shallow ST changes greatly, which is 
355 consistent with the obtained results. The results above indicate that the $20 \mathrm{~cm} \mathrm{ST}$

356 increase trend of the Qinghai-Tibet Plateau is obvious, and there are significant 357 regional differences. 

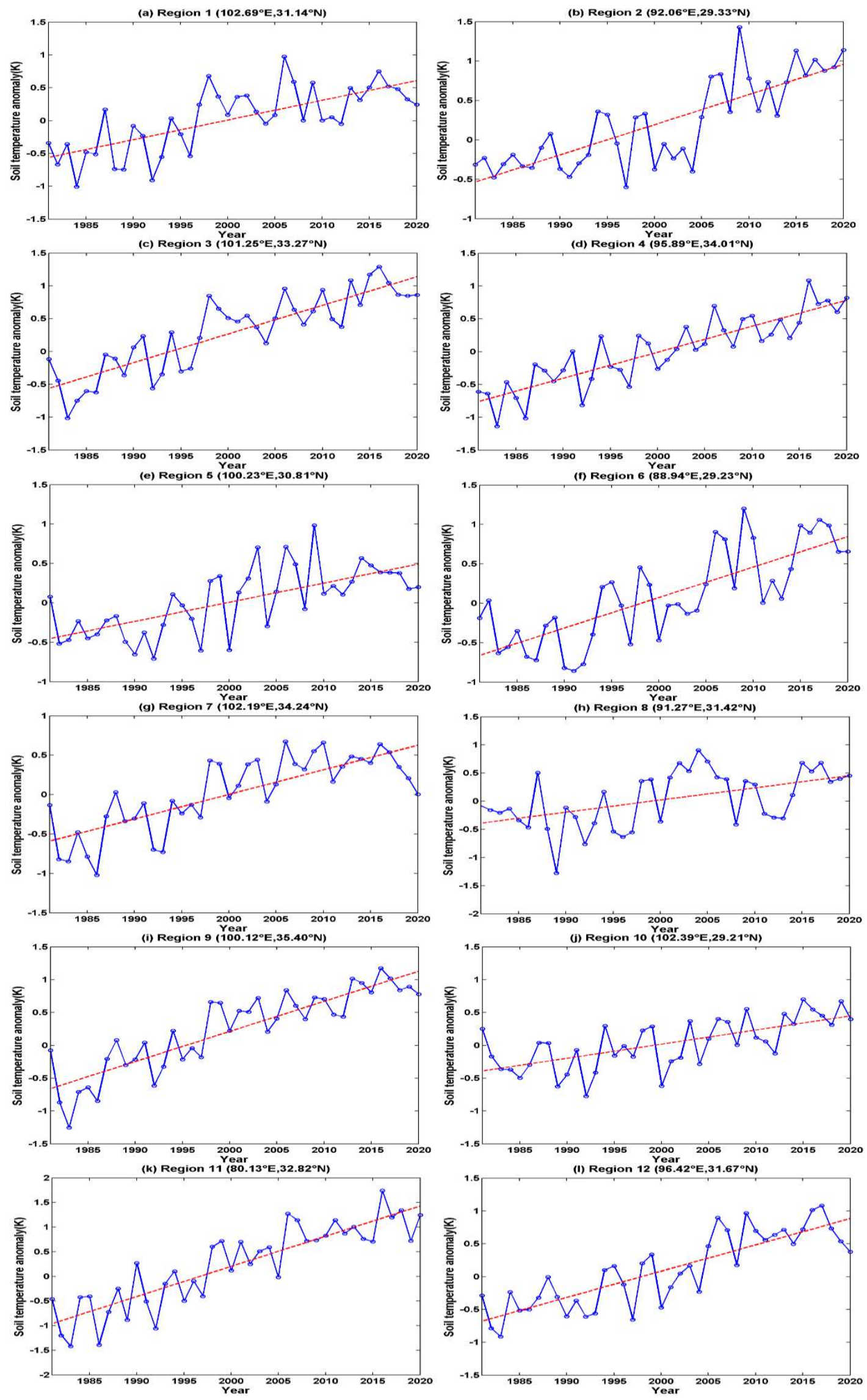

Fig. 8. Interannual variation of $20 \mathrm{~cm}$ ST anomalies in 12 regions of the Qinghai-Tibet

Plateau (unit: K) 


\subsection{Spatial variation characteristics of $20 \mathrm{~cm} \mathrm{ST} \mathrm{on} \mathrm{the} \mathrm{Qinghai-Tibet} \mathrm{Plateau}$}

Fig. 9 shows the spatial distribution of $20 \mathrm{~cm}$ ST anomalies in the Qinghai-Tibet Plateau from 1981 to 2020 . It can be seen from the figure that since 1981-2000, most areas of the Qinghai-Tibet Plateau have been in the cold stage, and the northwestern part of the Qinghai-Tibet Plateau is a strong and obvious center of $20 \mathrm{~cm}$ negative ST, especially from 1981 to 1986 . This negative anomaly center lasted for almost 20 years.

In addition, from 1981 to 2000 , there were also four positive anomaly centers in the Qinghai-Tibet Plateau, namely the eastern part of the Qinghai-Tibet Plateau, the central-eastern part of the Qinghai-Tibet Plateau, the southern part of the Qinghai-Tibet Plateau, and the southwestern part of the Qinghai-Tibet Plateau. Among them, the positive anomaly of southwestern part of the Qinghai-Tibet Plateau was strong in some years (such as 1984, 1999), reaching above $2 \mathrm{~K}$, and in some years (such as 1991, 1997), it was weak, below $0.5 \mathrm{~K}$, or even disappear. In most years from 1981 to 2000 , the positive anomaly of $20 \mathrm{~cm} \mathrm{ST} \mathrm{in} \mathrm{the} \mathrm{southern} \mathrm{part} \mathrm{of} \mathrm{the}$ Qinghai-Tibet Plateau was strong, reaching above $2.5 \mathrm{~K}$, while in some years (such as 1990 and 1991), it was relatively weak, near 0.5-1 K.

In 1986 and 1993, there was an obvious positive anomaly center in the north-central Qinghai-Tibet Plateau. From 1981 to 1986, the ST of $20 \mathrm{~cm}$ in central and northern Tibet had an obvious trend of rapid temperature decrease and then rapidly increase. The annual temperature reached $-1.5-2.5 \mathrm{~K}$. The ST of $20 \mathrm{~cm}$ changed significantly from 1990 to 1995 , and its annual temperature change rate reached $-1.5-1.5 \mathrm{~K}$.

From 2001 to 2005 , there was a negative anomaly center of about $-1 \mathrm{~K}$ in central Tibet. The positive anomaly center in southwestern Tibet disappeared, while the positive anomaly center in southern Tibet remained strong. In 2002, the $20 \mathrm{~cm}$ ST in southern Tibet reached a positive anomaly, up to $2 \mathrm{~K}$ or more. In addition, the strong positive anomaly center in the eastern part of the Qinghai-Tibet Plateau disappeared in 2005 after having remained for 24 years (1981-2004). The strong positive anomaly 
center of ST in central and eastern part of the Qinghai-Tibet Plateau, having existed for 22 years (1981-2003, except 2002), disappeared in 2004.

Based on the interannual variation of the $20 \mathrm{~cm}$ ST anomaly in Figure 3(d1), the 20 cm ST anomaly across the Qinghai-Tibet Plateau has changed from a negative value to a positive value since 2006. It can also be seen from Figure 9 that since 2006, the negative ST anomaly of $20 \mathrm{~cm}$ in most parts of the Qinghai-Tibet Plateau has begun to rise. Except for the scattered negative anomaly centers, soil temperature anomalies in most parts of the Qinghai-Tibet Plateau have changed between $-0.5 \mathrm{~K}$ and $0.5 \mathrm{~K}$.

It is worth noting that since 1981, the vast northwestern part of the Qinghai-Tibet Plateau has disappeared from the strong negative anomaly center that lasted for nearly 20 years. In the southern part of the Qinghai-Tibet Plateau, the positive and negative anomaly centers appear at intervals. For example, a strong positive anomaly center appeared in 2006, followed by a negative anomaly center that lasted for 7 years (2007-2013). Afterwards, the positive anomaly center that has been in existence for 7 years (2014-2020) appeared. A relatively weak positive anomaly center appeared in the northeastern part of the Qinghai-Tibet Plateau for 17 years (2004-2020). The intensity was $0.5-1 \mathrm{~K}$ during 2004-2012, and it slightly strengthened after 2012. The $20 \mathrm{~cm}$ ST anomaly varies between 1-1.5 K.

The above analysis shows that the ST of $20 \mathrm{~cm}$ in the Qinghai-Tibet Plateau has significant temporal and spatial changes. From 1981 to 2000, most areas of the Qinghai-Tibet Plateau were in the cold stage; especially the northwestern region was a strong negative soil temperature anomaly. Since 2006, the $20 \mathrm{~cm}$ ST anomaly has changed from a negative value to a positive value. From the perspective of spatial distribution, there was a strong negative ST anomaly center in the northwestern region from 1981 to 2000. Four positive anomalous centers generally exist in the Qinghai-Tibet Plateau, namely the eastern part of the Qinghai-Tibet Plateau (24 years, 1981-2004), the central-eastern part of the Qinghai-Tibet Plateau (22 years, 1981-2003, except 2002), and the southern part of the Qinghai-Tibet Plateau (continued 26 years, 1981-2006), the southwestern Qinghai-Tibet Plateau (19 years, 
419 1981-1999). In addition, since 2004, there has been a weaker positive anomaly center

420 in the northeastern part of the Qinghai-Tibet Plateau that lasted for 17 years 421 (2004-2020). 

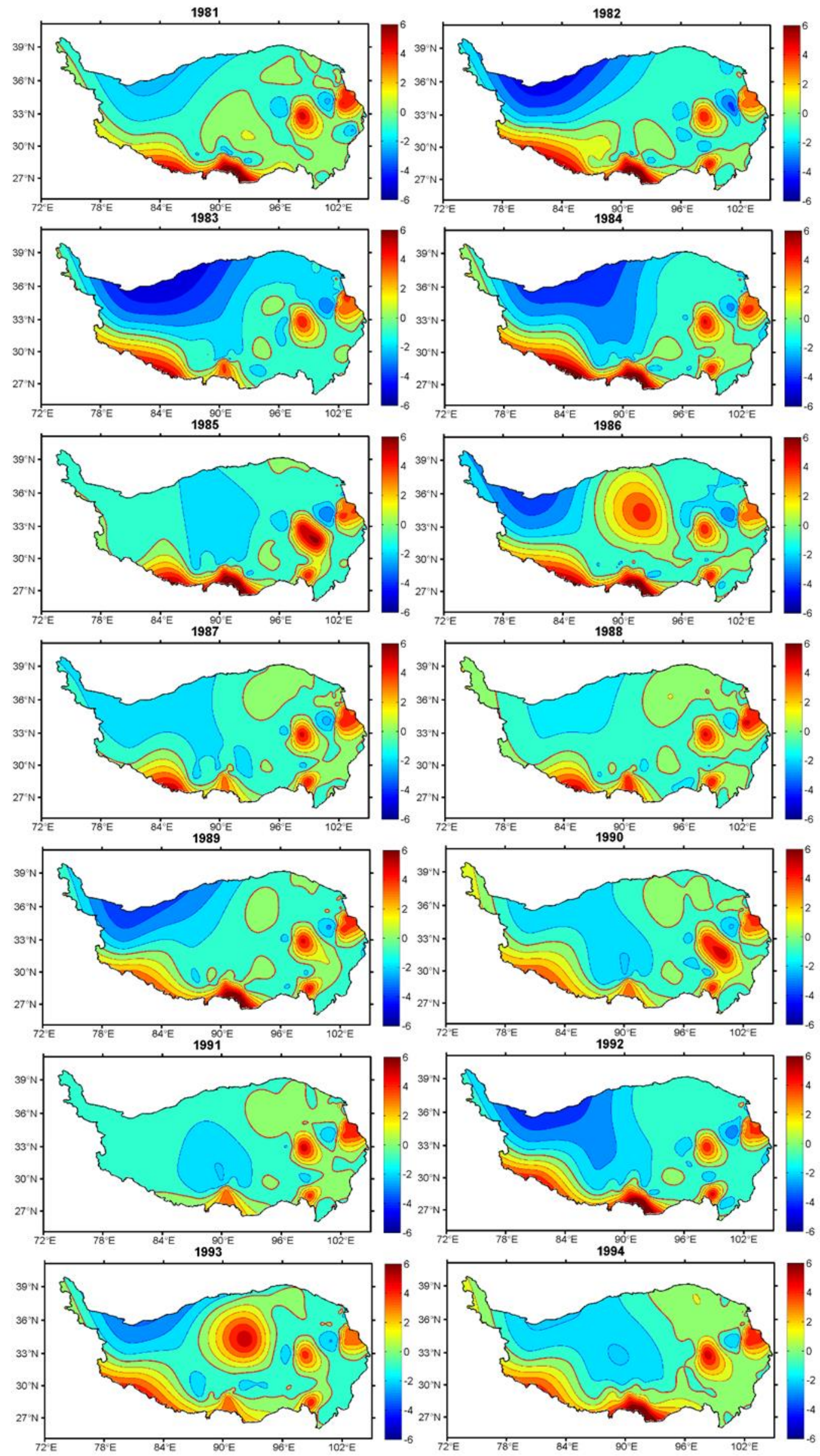

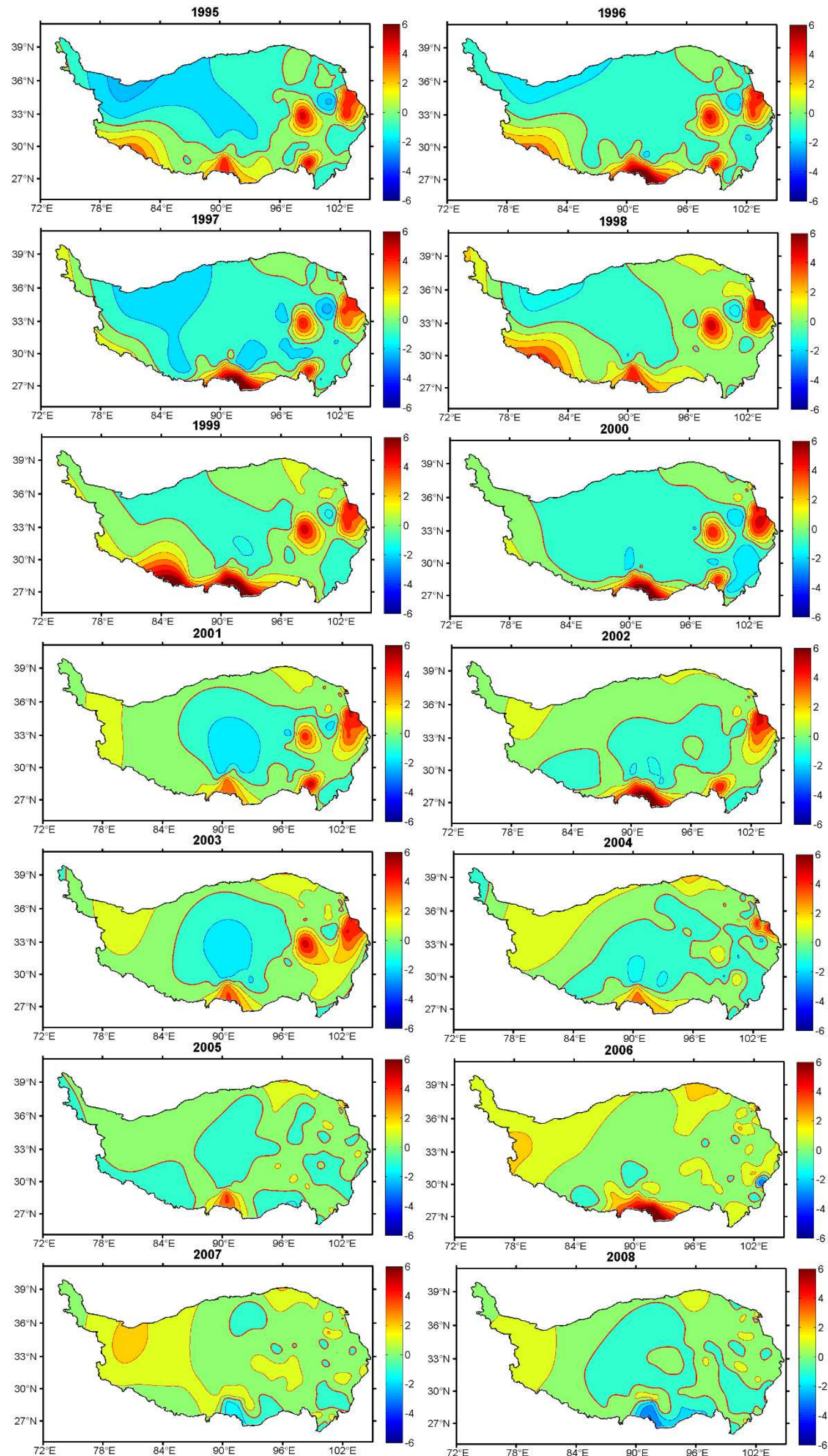

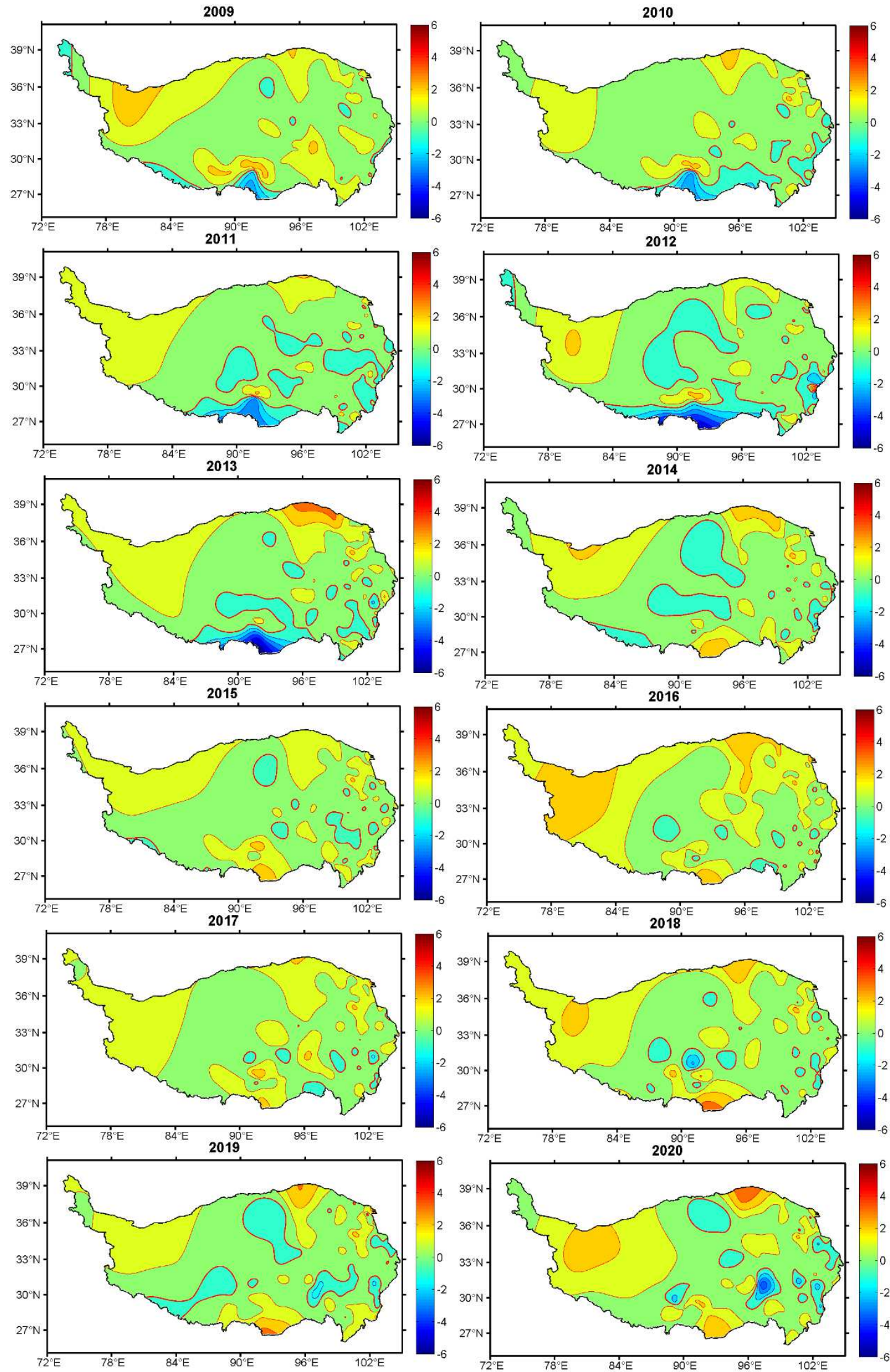

Fig. 9. Spatial distribution of $20 \mathrm{~cm}$ ST anomalies in the Qinghai-Tibet Plateau from 1981 to 2020 (unit: K)

3.4. Temporal change characteristics of $20 \mathrm{~cm}$ ST on the Qinghai-Tibet Plateau 
(reanalysis data)

429 Fig. 10 shows the $20 \mathrm{~cm}$ ST anomaly and its MK test using the reanalysis data.

430 Because the surface layer of the shallow soil does not change much, we chose the observational data of $20 \mathrm{~cm}$ and reanalysis data of $18.5 \mathrm{~cm}$ (layer 2) for comparative analysis. It can be seen from Fig. 10(a) that the ST of the reanalyzed data also shows an upward trend, and the interdecadal variability is $0.22 \mathrm{~K} / 10 \mathrm{a}$, which is less than the $0.5 \mathrm{~K} / 10 \mathrm{a}$ of the observational data. The $18.5 \mathrm{~cm}$ ST anomaly also varies between -1 $\mathrm{K}$ and $1 \mathrm{~K}$, and the amplitude is also smaller than the observational data. In the MK test in Fig. 10(b), there is a significant mutation point near 1998, which is different from the result obtained from the observational data that there is an insignificant mutation point in 2008 .

The above results indicate that when using the shallow ST data of the

Qinghai-Tibet Plateau in the study, detection and discrimination are needed. 


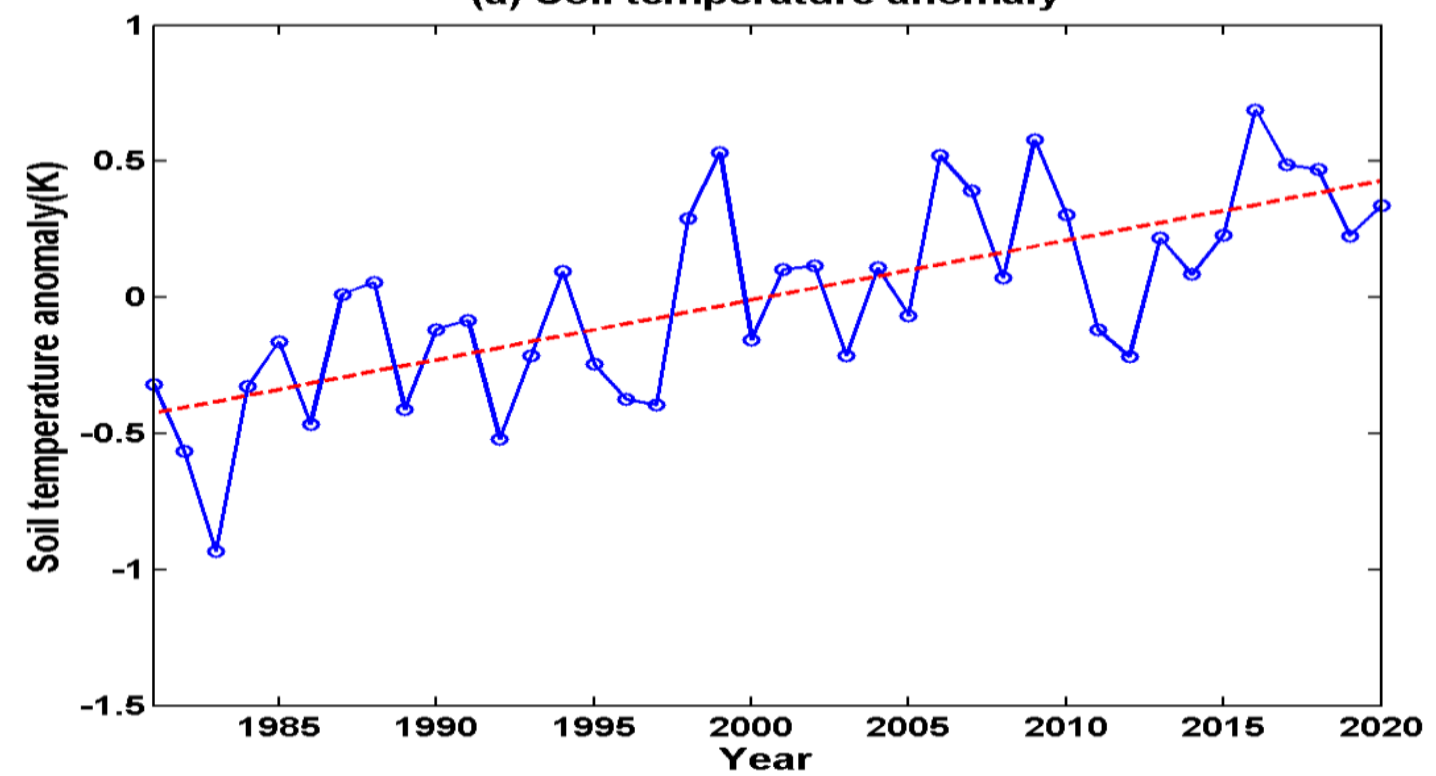

(b) Mann-Kendall statistic

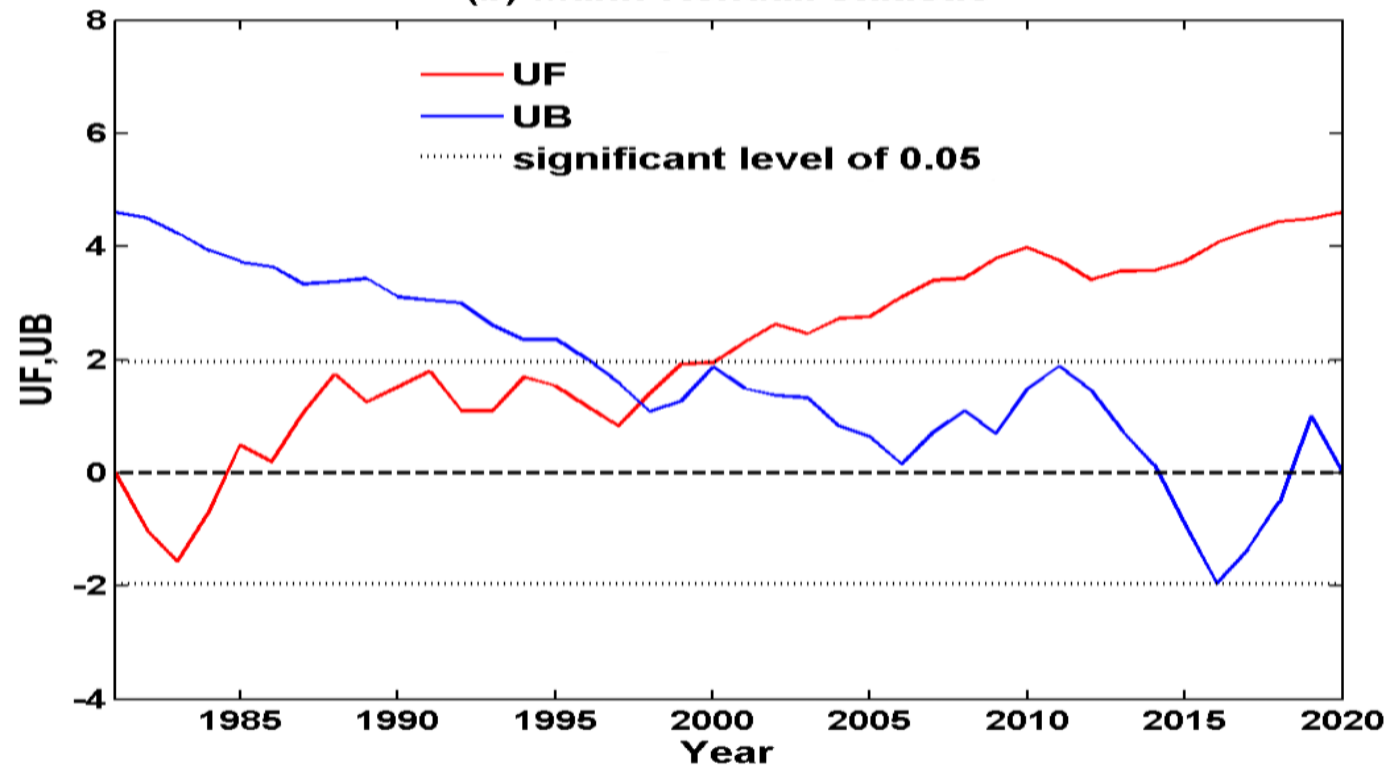

Fig. 10. Interannual variation and MK analysis of the $20 \mathrm{~cm}$ ST anomaly on the Qinghai-Tibet Plateau (reanalysis data, unit: K)

\section{Conclusion}

Shallow soil temperature (ST) and its temporal as well as spatial changes directly or indirectly affect many processes that occur in the soil, such as seed germination, root elongation, evaporation, storage and movement of water and microorganisms, nutrient cycling, and many other dynamics of the soil process. $20 \mathrm{~cm}$ is used as the boundary layer between the surface layer of shallow soil $(0-20 \mathrm{~cm})$ and the bottom layer of shallow soil $(20-40 \mathrm{~cm})$, the study of its temporal and spatial characteristics is necessary. Based on observational data and reanalysis data, this paper studies the 
abnormal conditions of the shallow ST of the Qinghai-Tibet Plateau from 1981 to 2020, and further analyzes the temporal as well as spatial characteristics of the $20 \mathrm{~cm}$ ST. This work is of great significance for understanding the soil thermal activity in the Qinghai-Tibet Plateau in recent decades.

The $20 \mathrm{~cm}$ ST on the Qinghai-Tibet Plateau gradually decreases from south to north, and from east to west. The average ST in the Western Sichuan Plateau, located in the southeast of the Qinghai-Tibet Plateau is the highest, with $T_{20 \mathrm{~cm}}=18.1^{\circ} \mathrm{C}$. The temperature in the central and northern part of the Qinghai-Tibet Plateau is the lowest, with $T_{20 \mathrm{~cm}}=4.9^{\circ} \mathrm{C}$. The temperature increase of $0-20 \mathrm{~cm}$ (the surface layer of shallow soil) is roughly the same, which is quite different from that of $40 \mathrm{~cm}$ (the bottom layer of shallow soil). The average annual ST of $0-20 \mathrm{~cm}$ is $9.15-9.57{ }^{\circ} \mathrm{C}$, and the interdecadal variability of $0-20 \mathrm{~cm}$ is $0.49-0.53 \mathrm{~K} / 10 \mathrm{a}$. The average annual ST of $40 \mathrm{~cm}$ is $8.69^{\circ} \mathrm{C}$, and the interdecadal variability of $40 \mathrm{~cm}$ reaches $0.98 \mathrm{~K} / 10 \mathrm{a}$.

In terms of spatial distribution, there was a strong negative ST anomaly center in the northwestern part of the Qinghai-Tibet Plateau from 1981 to 2000. Four positive anomalous centers generally exist in the Qinghai-Tibet Plateau, namely the eastern part of the Qinghai-Tibet Plateau (24 years, 1981-2004), the central-eastern part of the Qinghai-Tibet Plateau (22 years, 1981-2003, except 2002), and the southern part of the Qinghai-Tibet Plateau (26 years, 1981-2004). Years, 1981-2006), Southwestern Qinghai-Tibet Plateau (19 years, 1981-1999). In addition, since 2004, there has been a weaker positive anomaly center in the northeastern part of the Qinghai-Tibet Plateau that lasted for 17 years (2004-2020).

According to the ST of $20 \mathrm{~cm}$, the Qinghai-Tibet Plateau can be divided into 12 regions. The temperature increase trend of each region is obvious, and there are certain regional differences. The average value of different regions ranges from $4.3{ }^{\circ} \mathrm{C}$ (region 4, Qaidam Plateau) to $18.1{ }^{\circ} \mathrm{C}$ (region 10, Southeast Qinghai-Tibet Plateau), and the average difference is nearly $14 \mathrm{~K}$. The standard deviation of different regions ranges from 0.38 K (region 10, Southeast Qinghai-Tibet Plateau) to $0.82 \mathrm{~K}$ (region 11, North Qiangtang Plateau). 


\section{References}

Bezdek JC, Ehrlidh R, Full W (1984) FCM: the fuzzy C-means clustering algorithm. Comput Geosci 10: 191-203. https://doi.org/10.1016/00983004(85)90094-9

Cheng GD, Wu TH (2007) Responses of permafrost to climate change and their environmental significance, Qinghai-Tibet Plateau. J Geophys Res Earth Surf 112: F02S03. https://doi.org/10.1029/2006JF000631

Deng XS, Tang ZA (2011) Moving surface spline interpolation based on Green's function. Math Geosci 43: 663-680. https://doi.org/10.1007/s11004-011-9346-5

Dickinson RE (1995) Land-atmosphere interaction. Rev Geophys 33: 917-922. https://doi.org/ 10.1029/ 95RG00284

Douville H, Colin J, Krug E, Cattiaux J, Thao S (2016) Midlatitude daily summer temperatures reshaped by soil moisture under climate change. Geophys Res Lett 43: 812-818. https://doi.org/10.1002/2015g1066222

Duan AM, Wang MR, Lei YH, Cui YF (2013) Trends in Summer Rainfall over China Associated with the Tibetan Plateau Sensible Heat Source during 1980-2008. J Climate 26: 261-275. https://doi.org/ 10.1175/JCLI-D-11-00669.1

Guo DL, Wang HJ (2016) Permafrost degradation and associated ground settlement estimation under $2{ }^{\circ} \mathrm{C}$ global warming. Clim Dyn 49: 2569-2583. https://doi.org/10.1007/s00382-016-3469-9

Holmes TRH, Owe M, De Jeu RAM, Kooi H (2008) Estimating the soil temperature profile from a single depth observation: A simple empirical heatflow solution. Water Resour Res 44: W02412. https://doi.org/10.1029/2007WR005994

Hu Q, Feng S (2005) How have soil temperatures been affected by the surface temperature and precipitation in the Eurasian continent? Geophys Res Lett 32: 57-76. https://doi.org/ 10.1029/2005GL023469

Huang F, Zhan WF, Ju WM, Wang ZH (2014) Improved reconstruction of soil thermal field using two-depth measurements of soil temperature. J Hydrol 519: 711-719. https://doi.org/10.1016/ j.jhydrol.2014.08.014

Jiang XW, Li YQ, Yang S, Yang K, Chen JW (2016) Interannual Variation of Summer 
Atmospheric Heat Source over the Tibetan Plateau and the Role of Convection around the Western Maritime Continent. J Climate 29: 121-138. https://doi.org/10.1175/JCLI-D-15-0181.1

Kang SC, Xu YW,You QL, Flügel WA, Pepin N, Yao TD (2010) Review of climate and cryospheric change in the Tibetan Plateau. Environ Res Lett 5: 015101. http://dx.doi.org/10.1088/1748-9326/5/1/015101

Kendall M (1975) Rand Correlation Methods. London: Charles Griffin, pp 13-26

Kirschbaum MUF (1995) The temperature-dependence of soil organic-matter decomposition, and the effect of global warming on soil organic-C storage. Soil Biol Biochem 27: 753-760. https://doi.org/10.1016/0038-0717(94)00242-S

Krarti M, Lopez-Alonzo C, Claridge DM, Kreider JF (1995) Analytical model to predict annual soil surface temperature variation. J Sol Energy Eng 117: 91-99. https://doi.org/ 10.1115/1.2870881

Kunkel V, Wells T, Hancock GR (2016) Soil temperature dynamics at the catchment scale. Geoderma 273: 32-44. https://doi.org/10.1016/j.geoderma.2016.03.011

Lee M (2009) Improvement of the Fuzzy C-Means Clustering Algorithm with Adaptive Learning of the Dissimilarities among Categorical Feature Values. 2009 IEEE-Int Conf Fuzzy Syst 1-3: 403-408. https://doi.org/10.1109/FUZZY.2009.5277209

Liang LL, Riveros-Iregui DA, Emanuel RE, McGlynn BL (2014) A simple framework to estimate distributed soil temperature from discrete air temperature measurements in data-scarce regions. J Geophys Res: Atmos 119: 407-417. https://doi.org/10.1002/2013jd020597

Lin ZY, Wu XD (1981) Climate Regionalization of the Qinghai-Xizang Plateau. Acta Geographica Sinica 36: 22-32. https://kns.cnki.net/kcms/detail/detail.aspx?dbcode=CJFD\& dbname $=$ CJFD7984\&filename $=$ DLXB198101002 \&v $=$ FO8T6pExVyGBpcx\%25m md2B0QDpHTdHB33RO7F8jQPjRVpNe6raxGyWM18bwvdaq7FxyiY5

Liu WD, You HL, Ren GY, Yang P, Zhang BZ (2014) AWS precipitation 
characteristics based on K-means clustering method in Beijing area. Meteorol Monogr 40: 844-851. https://doi.org/ 10.7519/jissn1000-0526.2014.07.008

Liu XD, Chen BD (2000) Climatic warming in the Tibetan Plateau during recent decades. Int J Climatol 20: 1729-1742. https://doi.org/10.1002/1097-0088(20001130)20:14<1729::AIDJOC 556>3.0.CO;2-Y

Liu XS, Luo TX (2011) Spatiotemporal variability of soil temperature and moisture across two contrasting timberline Ecotones in the Sergyemla Mountains, Southeast Tibet. Arct Antarct Alp Res 43: 229-238. https://doi.org/10.1657/1938-4246-43.2.229

Liu YQ, Avissar R (1999) A study of persistence in the land-atmosphere system with a fourth-order analytical model. J Climate 12: 2154-2168. https://doi.org/10.1175/1520-0442(1999) 012<2154:ASOPIT>2.0.CO;2

Luo DL, Jin HJ, Jin XY, He RX, Li XY, Muskett RR, Marchenko SS, Romanovsky VE (2018b) Elevation-dependent thermal regime and dynamics of frozen ground in the Bayan Har Mountains, northeastern Qinghai-Tibet Plateau, southwest China. Permafr Periglac Process 29: 257-270. https://doi.org/10.1002/ ppp.1988

Luo GJ, Kiese R, Wolf B, Butterbach-Bahl K (2013) Effects of soil temperature and moisture on methane uptake and nitrous oxide emissions across three different ecosystem types. Biogeosciences 10: 305-321. https://doi.org/10.5194/bg-10-3205-2013

Ma WQ, Ma YM, Su B (2011) Feasibility of retrieving land surface heat fluxes from Aster data using SEBS: a case study from NamCo Area of the Tibetan Plateau. Arct Antarct Alp Res 43: 239-245. https://doi.org/10.1657/1938-4246-43.2.239

Mackay AD, Barber SA (1984) Soil-temperature effects on root-growth and phosphorus uptake by corn. Soil Sci Soc Am J 48: 818-823. https://doi.org/10.2136/ sssaj1984.03615 9950048000 40024x

Mann HB (1945) Nonparametric tests against trend. Econom 13: 245-259. https://doi.org/10.2307/1907187 
Mellander PE, Löfvenius MO, Laudon H (2007) Climate change impact on snow and soil temperature in boreal scots pine stands. Clim Chang 85: 179-193. https://doi.org/ 10.1007/s10584-007-9254-3

Paul KI, Polglase PJ, Smethurst PJ, O'Connell AM, Carlyle CJ, Khanna PK (2004) Soil temperature under forests: a simple model for predicting soil temperature under a range of forest types. Agric For Meteorol 121: 167-182. https://doi.org/10.1016/ j.agrformet.2003.08.030

Peng XO, Frauenfeld W, Cao B, Wang K, Wang H, Su H, Huang Z, Yue D, Zhang T (2016) Response of changes in seasonal soil freeze/thaw state to climate change from 1950 to 2010 across China. J Geophys Res Earth Surf 121: 1984-2000. https://doi.org/ 10.1002/2016JF003876

Qin YH, Liu W, Guo Z, Xue S (2020) Spatial and temporal variations in soil temperatures over the Qinghai-Tibet Plateau from 1980 to 2017 based on reanalysis products. Theor Appl Climatol 140: 1055-1069. https://doi.org/10.1007/s00704-020-03149-9

Samadianfard S, Asad E, Jarhana S, Kazemi H, Kheshtgar S, Kisi O, Sajjadi S, Manaf AA (2018) Wavelet neural networks and gene expression programming models to predict short-term soil temperature at different depths. Soil Tillage Res 175: 37-50. https://doi.org/ 10.1016/j.still. 2017.08.012

Park HS, Chiang JCH, Bordoni S (2012) The Mechanical Impact of the Tibetan Plateau on the Seasonal Evolution of the South Asian Monsoon. J Climate 25: 2394-2407. https://doi.org/ 10.1175/JCLI-D-11-00281.1

Saxena A, Prasad M, Gupta A, Gupta A, Bharill N, Patel OP, Tiwari A, Er MJ, Ding W, Lin C (2017) A review of clustering techniques and developments. Neurocomputing 267: 664-681. https://doi.org/10.1016/j.neucom.2017.06.053

Su Z, Wen J, Dente L, van der Velde R, Wang L, Ma Y, Yang K, Hu Z (2011) The Tibetan Plateau observatory of plateau scale soil moisture and soil temperature (Tibet-Obs) for quantifying uncertainties in coarse resolution satellite and model products. Hydrol Earth Syst Sci 15: 2303-2316. 
https://doi.org/10.5194/hess-15-2303-2011

Tang MC, Shen ZB, Chen YY (1979) On climatic characteristics of the Xizang Plateau monsoon. Acta Geograph Sin 34: 34-42. https://kns.cnki.net/kcms/detail/detail.aspx?dbcode=CJFD $\&$ dbname $=$ CJFD7984\&filename $=$ DLXB197901003 $\& v=D 1$ IdnHEP13\%25mmd 2 BCJBTcGum5zBGAfUD6q0LpjSII0XT\%25mmd2BH\%25mmd2FFriKAu5\%25m md2FDw6eEDSKgJOkXR

Tang MC, Wang JX, Zhang J (1987) A primary method for predicting the spring rainfall by the winter soil temperature depth $80 \mathrm{~cm}$. Plateau Meteorol 6: 244-255. https://kns.cnki.net/ $\mathrm{kcms} /$ detail/detail. aspx $? \mathrm{dbcode}=\mathrm{CJFD} \& \mathrm{dbname}=\mathrm{CJFD} 8589 \&$ filename $=\mathrm{GYQX} 19$ 8703005\&v=CrUDrXz03wBIDGdBU\%25mmd2B92QXLeRxs14Z1lguvAaelHVI U0VJFMxTFyK0lq8EbVBSmc

Wang CH, Yang K, Li YL, Wu D, Bo Y (2017) Impacts of Spatiotemporal Anomalies of Tibetan Plateau Snow Cover on Summer Precipitation in Eastern China. J Meteorol Res 30: 885-903. https://doi.org/ 10.1175/JCLI-D-16-0041.1

Wang YH, Chen W, Zhang JY, Nath D (2013) Relationship Between Soil Temperature in May over Northwest China and the East Asian Summer Monsoon Precipitation. J Meteorol Res 27: 716-724. https://doi.org/10.1007/s13351-013-0505-0

Wessel P (2009) A general-purpose Green's function-based interpolator. Comput Geosci 35: 1247-1254. https://doi.org/10.1016/j.cageo.2008.08.012

Wu TW, Qian ZA (2003) The relation between the Tibetan winter snow and the Asian summer monsoon and rainfall: An observational investigation. J Climate 16: 2038-2051. https://doi.org/0.1175/520-0442(2003)016<2038:TRBTTW>2.0.CO;2

Wu W, Tang XP, Guo NJ, Yang C, Liu HB, Shang YF (2013) Spatiotemporal modeling of monthly soil temperature using artificial neural networks. Theor Appl Climatol 113: 481-494. https://doi.org/10.1007/s00704-012-0807-7

Wu XB, Nan ZT, Zhao SP, Zhao L, Cheng GD (2018b) Spatial modeling of permafrost distribution and properties on the Qinghai-Tibet Plateau. Permafr 
Periglac Process 29: 86-99. https://doi.org/ 10.1002/ppp.1971

Wundram D, Pape R, Löffler J (2010) Alpine soil temperature variability at multiple scales. Arct Antarct Alp Res 42: 117-128. https://doi.org/10.1657/1938-4246-42.1.117

Yan D, Li JQ, Pei JM, Cui J, Nie M, Fang CM (2017) The temperature sensitivity of soil organic carbon decomposition is greater in subsoil than in topsoil during laboratory incubation. Sci Rep 7: 5181. https://doi.org/10.1038/s41598-017-05293-1

Yang K, Wu H, Qin J, Lin CJ, Tang WJ, Chen YY (2014) Recent climate changes over the Tibetan Plateau and their impacts on energy and water cycle: a review. Glob Planet Chang 112: 79-91. https://doi.org/10.1016/j.gloplacha.2013.12.001 Yang MX, Yao TD, Gou XH, Tang HG (2007) Water recycling between the land surface and atmosphere on the northern Tibetan Plateau — a case study at flat observation sites. Arct Antarct Alp Res 39: 694-698. https://doi.org/10.1657/1523-0430(07-509)[YANG]2.0.CO;2

Zhao L, Wu QB, Marchenko SS, Sharkhuu N (2010) Thermal State of Permafrost and Active Layer in Central Asia during the International Polar Year. Permafr Periglac Process 21: 198-207. https://doi.org/10.1002/ppp.688

Zhou XJ, Zhao P, Chen JM, Chen LX, Li WL (2009) Impacts of thermodynamic processes over the Tibetan Plateau on the Northern Hemispheric climate. Sci China Ser D Earth Sci 52: 1679-1693. https://doi.org/10.1007/s11430-009-0194-9

Zhou Y, Gao XQ, Zhang K, Li YJ, Yang LW (2020) Spatiotemporal variations in $3.2 \mathrm{~m}$ soil temperature in China during 1980-2017. Clim Dyn 54: 1233-1244. https://doi.org/10.1007/s00382-019-05055-x

Zhu FX, Cuo L, Zhang YX, Luo JJ, Lettenmaier DP, Lin YM, Liu Z (2018) Spatiotemporal variations of annual shallow soil temperature on the Tibetan Plateau during 1983-2013. Clim Dyn 51: 2209-2227. https://doi.org/10.1007/s00382-017-4008-z 